Supporting Information for:

\title{
Balancing Charge Transfer and Frenkel Exciton Coupling Leads to Excimer Formation in Molecular Dimers: Implications for Singlet Fission
}

Youn Jue Bae, ${ }^{\mathrm{a}}$ Daiki Shimizu, a,b Jonathan D. Schultz, ${ }^{\mathrm{a}}$ Gyeongwon Kang, ${ }^{\mathrm{a}}$ Jiawang Zhou, ${ }^{\mathrm{a}}$

George C. Schatz, ${ }^{a}$ Atsuhiro Osuka, ${ }^{\mathrm{b}}$ and Michael R. Wasielewski ${ }^{\mathrm{a}^{*}}$

${ }^{a}$ Department of Chemistry and Institute for Sustainability and Energy at Northwestern,

Northwestern University, Evanston IL 60208-3113

${ }^{b}$ Department of Chemistry, Graduate School of Science, Kyoto University

Sakyo-ku, Kyoto 606-8502, Japan

\section{Contents}

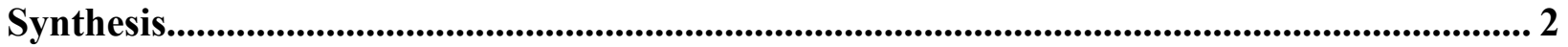

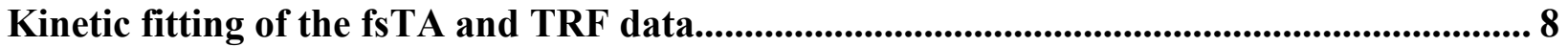

Steady state absorbance and emission ........................................................................................... 9

Additional TRF data ............................................................................................................ 10

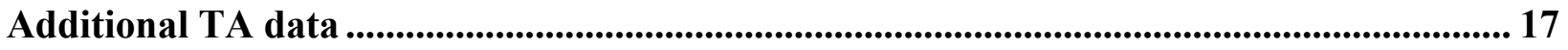

2ph DMF ................................................................................................................... 24

Computational Details ..................................................................................................... 26

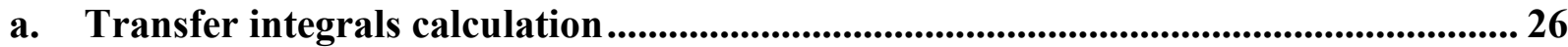

b. S1 energy calculation using TDDFT ............................................................................. 26

c. Charge transfer state energy calculation ............................................................................... 27

d. Exciton coupling $J$ calculation .................................................................................................. 27

e. Coulomb coupling in BPEA and DPP crystals............................................................... 31

f. Excimer eigenstates calculation ....................................................................................... 32

Triplet sensitization ............................................................................................................................ 41

Example input file for single-point energy of BPEA cation ...................................................... 43

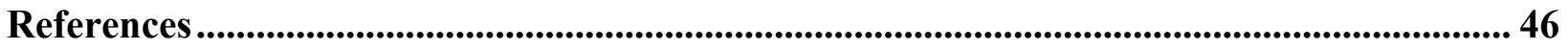




\section{Synthesis}

Instrumentation and Materials. All reagents and solvents were commercial reagent grade and were used without further purification unless where noted. Diisopropylamine was distilled from $\mathrm{CaH}_{2}$ before use. All reactions were carried out under $\mathrm{N}_{2}$ atmosphere. Preparative separations were performed by silica gel column chromatography. ${ }^{1} \mathrm{H}$ and ${ }^{13} \mathrm{C}$ NMR spectra were recorded on a Bruker Avance III $500 \mathrm{MHz}$ system equipped with a DCH CryoProbe, and chemical shifts were reported as the $\delta$ scale relative to internal standards $\mathrm{CHCl}_{3}\left(\delta=7.26 \mathrm{ppm}\right.$ for ${ }^{1} \mathrm{H}, 77.16 \mathrm{ppm}$ for $\left.{ }^{13} \mathrm{C}\right)$ or 1,1,2,2-tetrachloroethane- $d(\delta=6.00 \mathrm{ppm}$ for ${ }^{1} \mathrm{H}, 73.78$ ppm for $\left.{ }^{13} \mathrm{C}\right)$. 9-Ethynyl-10-phenylethynylanthracene was prepared according to a literature. ${ }^{1}$ High Resolution Mass Spectra (HRMS) were obtained with an Agilent LCTOF 6200 series mass spectrometer using electrospray ionization (ESI) and APPI.
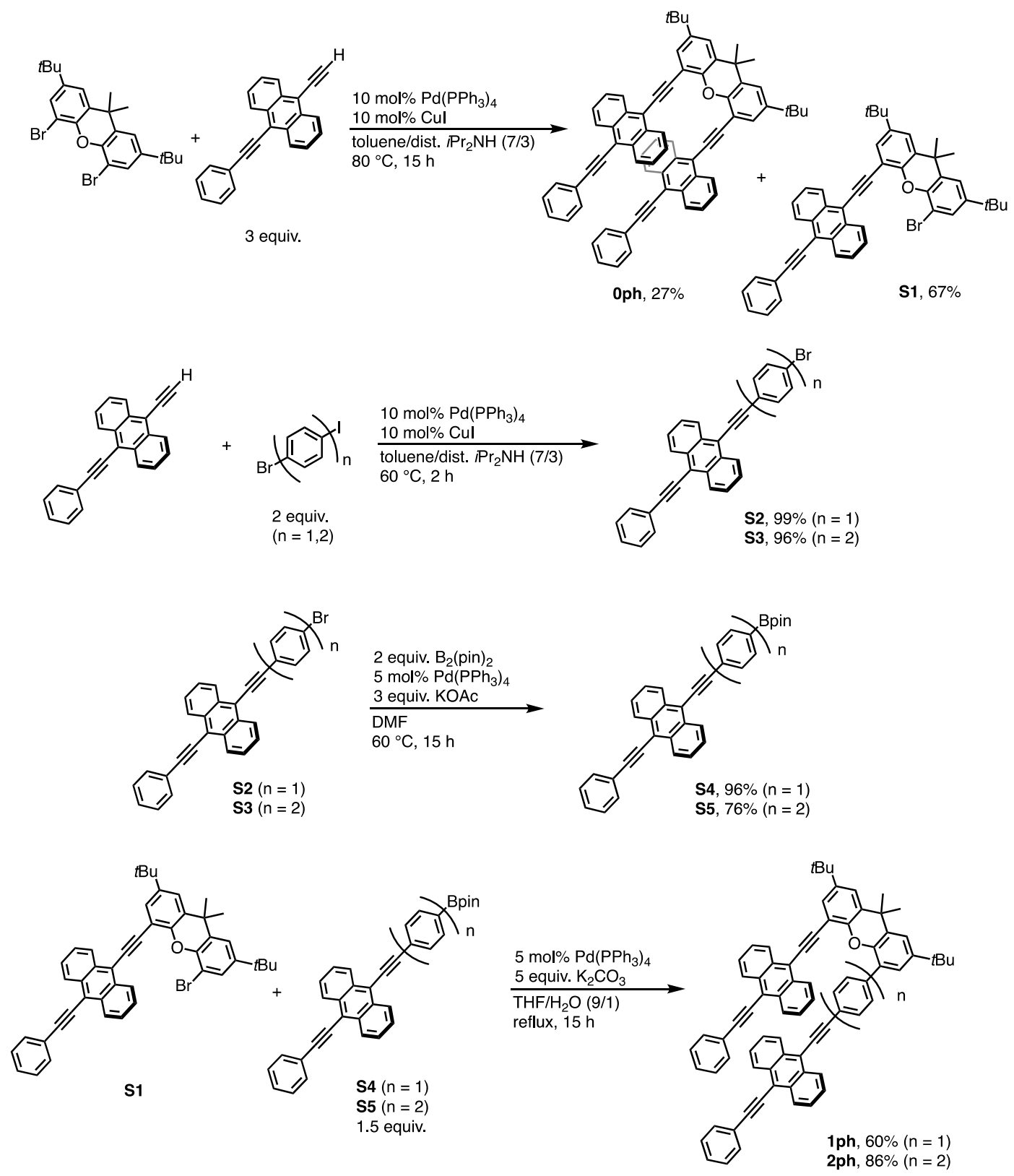

Scheme S1. Overview of the synthesis of $\mathbf{0 p h}, \mathbf{1 p h}$, and $\mathbf{2 p h}$. 


\section{Synthetic procedures.}

4,5-bis-(10-phenylethynylanthracen-9-ylethynyl)-2,7-di-tert-butyl-9,9-dimethylxanthene (0ph) and 4-bromo-5-(10-phenylethynylanthracen-9-ylethynyl)-2,7-di-tert-butyl-9,9-dimethylxanthene (S1)
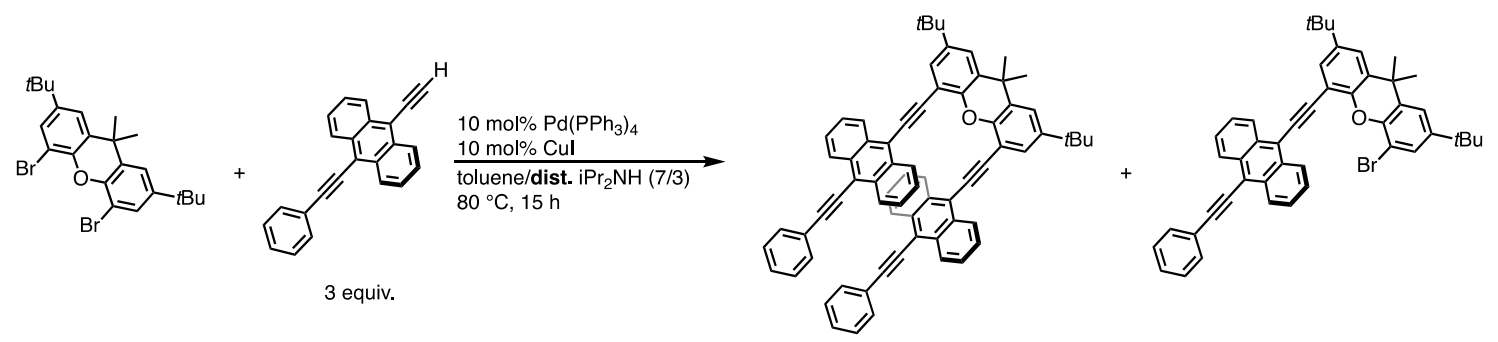

A mixture of 4,5-dibromo-2,7-di-tert-butyl-9,9-dimethylxanthene (120 mg, $0.25 \mathrm{mmol})$, 9-ethynyl-10phenylehynylanthracene (227 mg, $0.75 \mathrm{mmol}, 3$ equiv.), $\mathrm{Pd}\left(\mathrm{PPh}_{3}\right)_{4}(29 \mathrm{mg}, 10 \mathrm{~mol} \%)$, and $\mathrm{CuI}(4.8 \mathrm{mg}, 10$ mol\%) in toluene $/ i \operatorname{Pr}_{2} \mathrm{NH}(7 / 3 \mathrm{~mL})$ was stirred at $80{ }^{\circ} \mathrm{C}$ for $15 \mathrm{~h}$. The reaction mixture was extracted with $\mathrm{CH}_{2} \mathrm{Cl}_{2}$ and washed with water and brine. Organic mixture was separated and dried over anhydrous $\mathrm{Na}_{2} \mathrm{SO}_{4}$. The crude mixture was purified by silica gel column chromatography (eluent: $\mathrm{CH}_{2} \mathrm{Cl}_{2} /$ hexanes $=1 / 9$ ). Collected fractions were concentrated, and recrystallization from $\mathrm{MeOH}$ gave 4-bromo-5-(10phenylethynylanthracen-9-ylethynyl)-2,7-di-tert-butyl-9,9-dimethylxanthene (118 mg, $0.17 \mathrm{mmol}, 67 \%$ ) and 4,5-bis-(10-phenylethynylanthracen-9-ylethynyl)-2,7-di-tert-butyl-9,9-dimethylxanthene (62 mg, 68 $\mu \mathrm{mol}, 27 \%$ ), respectively.

0ph: ${ }^{1} \mathrm{H}$ NMR $\left(1,1,2,2\right.$-tetrachloroethane- $\left.d_{2}, 298 \mathrm{~K}\right) \delta / \mathrm{ppm}=8.39(\mathrm{t}, J=7.4 \mathrm{~Hz}, 4 \mathrm{H}), 8.14(\mathrm{~d}, J=8.5 \mathrm{~Hz}$, 4H), $7.64-7.58(\mathrm{~m}, 6 \mathrm{H}), 7.55(\mathrm{~d}, J=2.3 \mathrm{~Hz}, 2 \mathrm{H}), 7.33$ (t, $J=7.4 \mathrm{~Hz}, 2 \mathrm{H}), 7.27$ (t, $J=7.4 \mathrm{~Hz}, 5 \mathrm{H}), 7.18$ $(\mathrm{t}, J=7.4 \mathrm{~Hz}, 5 \mathrm{H}), 7.04(\mathrm{t}, J=7.4 \mathrm{~Hz}, 4 \mathrm{H}), 1.82(\mathrm{~s}, 6 \mathrm{H}), 1.43(\mathrm{~s}, 18 \mathrm{H}) ;{ }^{13} \mathrm{C}$ NMR $(1,1,2,2$-tetrachloroethane$\left.d_{2}, 298 \mathrm{~K}\right) \delta / \mathrm{ppm}=148.80,145.64,131.50,130.88,130.78,129.67,128.25,128.13,128.06,127.01,125.90$, $125.90,125.78,125.70,123.69,123.68,123.42,117.92,117.40,111.30,101.81,97.91,90.35,86.58,74.00$, 73.78, 73.56, 34.66, 34.40, 32.41, 31.38. ESI-HRMS $(\mathrm{m} / \mathrm{z})$ : calculated for $\mathrm{C}_{71} \mathrm{H}_{55} \mathrm{O}^{+}\left([M+\mathrm{H}]^{+}\right): 999.4247$, found: 923.4243 .

S1: ${ }^{1} \mathrm{H}$ NMR $\left(\mathrm{CDCl}_{3}, 298 \mathrm{~K}\right) \delta / \mathrm{ppm}=8.97(\mathrm{dd}, J=3.5,3.0 \mathrm{~Hz}, 2 \mathrm{H}), 8.70(\mathrm{dd}, J=3.5,3.0 \mathrm{~Hz}, 2 \mathrm{H}), 7.82-$ $7.77(\mathrm{~m}, 2 \mathrm{H}), 7.71-7.62(\mathrm{~m}, 5 \mathrm{H}), 7.52-7.41(\mathrm{~m}, 5 \mathrm{H}), 7.38(\mathrm{~d}, J=2.2 \mathrm{~Hz}, 1 \mathrm{H}), 1.71(\mathrm{~s}, 6 \mathrm{H}), 1.42(\mathrm{~s}, 9 \mathrm{H})$, $1.34(\mathrm{~s}, 9 \mathrm{H}) ;{ }^{13} \mathrm{C} \mathrm{NMR}\left(\mathrm{CDCl}_{3}, 298 \mathrm{~K}\right) \delta / \mathrm{ppm}=148.82,147.21,146.07,145.27,132.32,131.86,131.14$, 129.95, 128.94, 128.78, 128.74, 128.72, 128.43, 127.20, 127.01, 126.76, 123.83, 123.70, 121.97, 119.38, $118.33,111.58,110.57,102.35,98.90,90.67,86.82$, 77.41, 77.16, 76.91, 35.42, 34.74, 32.53, 31.74, 31.63, 31.56 . 
9-(4-bromophenylethynyl)-10-(phenylethynyl)anthracene S2
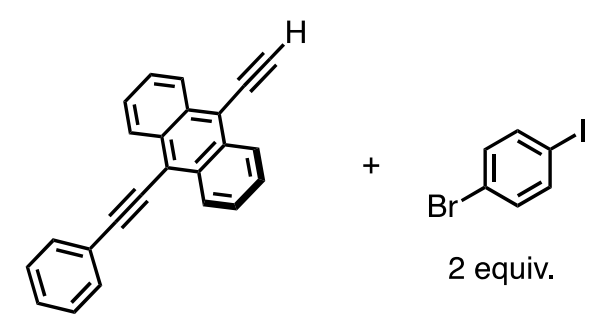

$10 \mathrm{~mol} \% \mathrm{Pd}\left(\mathrm{PPh}_{3}\right)_{4}$

$10 \mathrm{~mol} \% \mathrm{Cul}$

toluene/dist. $\mathrm{iPr}_{2} \mathrm{NH}(7 / 3)$

$60^{\circ} \mathrm{C}, 2 \mathrm{~h}$

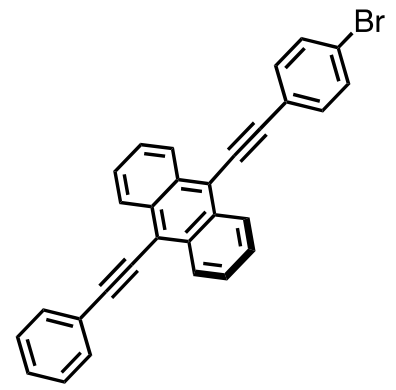

To a mixture of 1-bromo-4-iodobenzene (283 mg, $1.0 \mathrm{mmol}), \mathrm{Pd}\left(\mathrm{PPh}_{3}\right)_{4}(58 \mathrm{mg}, 0.05 \mathrm{mmol}, 10 \mathrm{~mol} \%)$, and $\mathrm{CuI}$ (4.8 mg, $0.05 \mathrm{mmol}, 10 \mathrm{~mol} \%)$ in toluene $/ i \operatorname{Pr}_{2} \mathrm{NH}(7 / 3 \mathrm{~mL})$, was added 9-ethynyl-10phenylehynylanthracene $(151 \mathrm{mg}, 0.50 \mathrm{mmol})$. After stirring at $60{ }^{\circ} \mathrm{C}$ for $3 \mathrm{~h}$, the reaction mixture was poured onto water and extracted with $\mathrm{CH}_{2} \mathrm{Cl}_{2}$. Organic phase was washed with brine and dried over anhydrous $\mathrm{Na}_{2} \mathrm{SO}_{4}$. The crude mixture was purified with silica gel column chromatography (eluent: $\mathrm{CH}_{2} \mathrm{Cl}_{2} /$ hexanes $\left.=1 / 9\right)$. Recrystallization from $\mathrm{MeOH}$ gave $\mathbf{S 2}(226 \mathrm{mg}, 0.50 \mathrm{mmol}, 99 \%)$.

${ }^{1} \mathrm{H} \mathrm{NMR}\left(\mathrm{CDCl}_{3}, 298 \mathrm{~K}\right) \delta / \mathrm{ppm}=8.73-8.68(\mathrm{~m}, 2 \mathrm{H}), 8.68-8.64(\mathrm{~m}, 2 \mathrm{H}), 7.79(\mathrm{dd}, J=8.3,1.6 \mathrm{~Hz}, 2 \mathrm{H})$, $7.69-7.62(\mathrm{~m}, 6 \mathrm{H}), 7.60(\mathrm{~d}, J=8.3 \mathrm{~Hz}, 2 \mathrm{H}), 7.50-7.41(\mathrm{~m}, 3 \mathrm{H}) ;{ }^{13} \mathrm{C} \mathrm{NMR}\left(\mathrm{CDCl}_{3}, 298 \mathrm{~K}\right) \delta / \mathrm{ppm}=$ $133.21,132.27,132.24,132.02,131.87,128.93,128.75,127.48,127.25,127.12,127.02,123.51,123.11$, $122.52,119.02,118.11,102.77,101.34,87.82,86.56,77.41,77.16,76.91$.

9-[4-(4,4,5,5-tetramethyl-1,3,2-dioxaborolan-2-yl)phenylethynyl]-10-phenylethynylanthracene (S4)
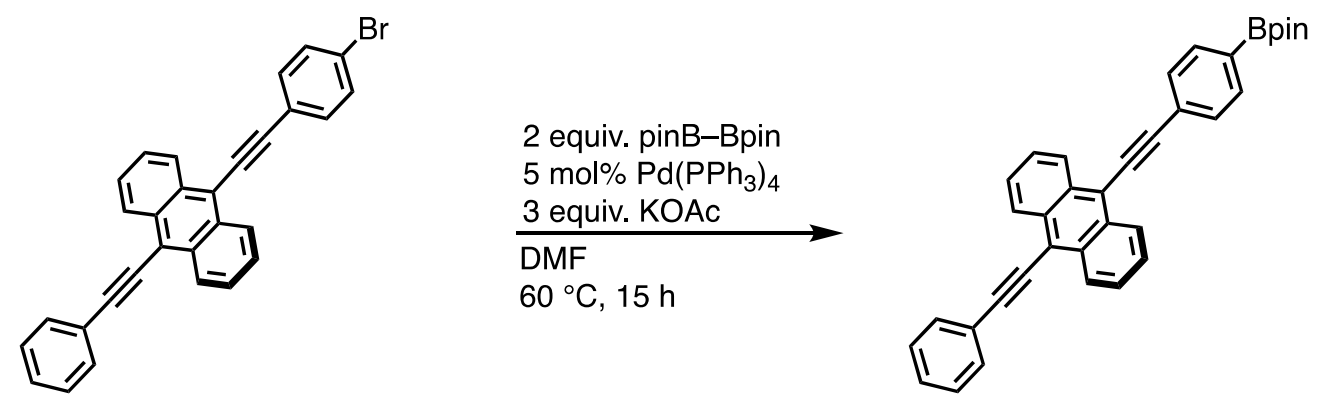

A mixture of $\mathbf{S 2}$ (137 mg, $0.30 \mathrm{mmol}), \mathrm{B}_{2}$ (pin) $)_{2}\left(152 \mathrm{mg}, 0.60 \mathrm{mmol}, 2\right.$ equiv.), $\mathrm{Pd}\left(\mathrm{PPh}_{3}\right)_{4}(17 \mathrm{mg}, 15 \mu \mathrm{mol}$, $5 \mathrm{~mol} \%)$, and KOAc ( $88 \mathrm{mg}, 0.90 \mathrm{mmol}, 3$ equiv.) in DMF $(30 \mathrm{~mL})$ was stirred at $80{ }^{\circ} \mathrm{C}$ for $15 \mathrm{~h}$. The reaction mixture was extracted with $\mathrm{CH}_{2} \mathrm{Cl}_{2}$ and washed with water and brine. Organic mixture was separated and dried over anhydrous $\mathrm{Na}_{2} \mathrm{SO}_{4}$. Recrystallization from $\mathrm{MeOH}$ gave $\mathbf{S} 4$ (145 mg, $0.29 \mathrm{mmol}$, $96 \%)$.

${ }^{1} \mathrm{H}$ NMR $\left(\mathrm{CDCl}_{3}, 298 \mathrm{~K}\right) \delta / \mathrm{ppm}=8.68-8.54(\mathrm{~m}, 4 \mathrm{H}), 7.80(\mathrm{~d}, J=8.0 \mathrm{~Hz}, 2 \mathrm{H}), 7.68(\mathrm{t}, J=7.6,6.6 \mathrm{~Hz}$, $4 \mathrm{H}), 7.59-7.51(\mathrm{~m}, 4 \mathrm{H}), 7.42-7.31(\mathrm{~m}, 4 \mathrm{H}), 1.29(\mathrm{~s}, 12 \mathrm{H}) ;{ }^{13} \mathrm{C} \mathrm{NMR}\left(\mathrm{CDCl}_{3}, 298 \mathrm{~K}\right) \delta / \mathrm{ppm}=134.96$, $132.31,132.25,131.86,130.97,128.88,128.74,127.42,127.06,127.01,126.20,123.57,118.83,118.48$, $102.73,102.66,87.97,86.63,84.21,77.41,77.16,76.91,25.07$. 
4-(10-phenylethynylanthracen-9-ylethynylphenyl)-5-(10-phenylethynylanthracen-9-ylethynyl)-2,7-ditert-butyl-9,9-dimethylxanthene (1ph)<smiles>CC(C)(C)c1cc(Br)c2c(c1)C(C)(C)c1cc(C(C)(C)C)cc(C#Cc3c4ccccc4c(C#Cc4ccccc4)c4ccccc34)c1O2</smiles><smiles>Brc1ccc(C#Cc2c3ccccc3c(C#Cc3ccccc3)c3ccccc23)cc1</smiles>
$5 \mathrm{~mol} \% \mathrm{Pd}\left(\mathrm{PPh}_{3}\right)_{4}$ 5 equiv. $\mathrm{K}_{2} \mathrm{CO}_{3}$ $\mathrm{THF} / \mathrm{H}_{2} \mathrm{O}(9 / 1)$ reflux, $15 \mathrm{~h}$

1.5 equiv.<smiles>CC(C)(C)c1cc(C#Cc2cc(C(C)(C)C)c(C#Cc3ccccc3)c3ccccc23)c2c(c1)C(C)(C)c1cc(C#Cc3ccccc3C#Cc3ccccc3)cc(-c3ccccc3C#Cc3ccccc3)c1O2</smiles>

A mixture of $\mathbf{S} 1(50 \mathrm{mg}, 71 \mu \mathrm{mol}), \mathbf{S} 4\left(54 \mathrm{mg}, 107 \mu \mathrm{mol}, 1.5\right.$ equiv.), $\mathrm{Pd}\left(\mathrm{PPh}_{3}\right)_{4}(4.1 \mathrm{mg}, 3.6 \mu \mathrm{mol}, 5$ mol\%), and $\mathrm{K}_{2} \mathrm{CO}_{3}(49 \mathrm{mg}, 0.36 \mathrm{mmol}, 5$ equiv.) in $\mathrm{THF} /$ water $(9 / 1 \mathrm{~mL})$ was heated to reflux for $15 \mathrm{~h}$. The reaction mixture was extracted with $\mathrm{CH}_{2} \mathrm{Cl}_{2}$ and washed with water and brine. Organic mixture was separated and dried over anhydrous $\mathrm{Na}_{2} \mathrm{SO}_{4}$. The crude mixture was purified by silica gel column chromatography (eluent: $\mathrm{CH}_{2} \mathrm{Cl}_{2}$ /hexanes). Recrystallization from $\mathrm{MeOH}$ gave 1ph (43 mg, $43 \mu \mathrm{mol}, 60 \%$ ).

${ }^{1} \mathrm{H}$ NMR $\left(\mathrm{CDCl}_{3}, 298 \mathrm{~K}\right) \delta / \mathrm{ppm}=8.44(\mathrm{~d}, J=7.7 \mathrm{~Hz}, 2 \mathrm{H}), 8.40(\mathrm{~d}, J=8.0 \mathrm{~Hz}, 2 \mathrm{H}), 8.19-8.14(\mathrm{~m}, 2 \mathrm{H})$, $8.14-8.10(\mathrm{~m}, 2 \mathrm{H}), 7.74(\mathrm{dd}, J=7.9,1.3 \mathrm{~Hz}, 2 \mathrm{H}), 7.62(\mathrm{~d}, J=8.3 \mathrm{~Hz}, 2 \mathrm{H}), 7.58(\mathrm{~d}, J=2.4 \mathrm{~Hz}, 1 \mathrm{H}), 7.55$ - $7.37(\mathrm{~m}, 13 \mathrm{H}), 7.26(\mathrm{~d}, J=2.3 \mathrm{~Hz}, 1 \mathrm{H}), 7.18-7.14(\mathrm{~m}, 3 \mathrm{H}), 6.88-6.80(\mathrm{~m}, 4 \mathrm{H}), 1.78(\mathrm{~s}, 6 \mathrm{H}), 1.40(\mathrm{~s}$, $9 \mathrm{H}), 1.38(\mathrm{~s}, 9 \mathrm{H}) ;{ }^{13} \mathrm{C} \mathrm{NMR}\left(\mathrm{CDCl}_{3}, 298 \mathrm{~K}\right) \delta / \mathrm{ppm}=149.52,146.08,145.69,145.50,138.17,132.28$, 132.20, 132.07, 132.02, 131.76, 131.24, 131.00, 130.34, 130.11, 129.62, 128.94, 128.72, 128.61, 128.10, $128.06,127.61,127.56,127.29,127.14,126.67,126.63,126.49$, 126.30, 126.22, 124.01, 123.66, 122.86, $122.41,121.49,119.43,119.02,118.66,117.96,111.42,102.72,101.97,101.95,98.45,90.64,87.21,86.59$, $86.21,77.41,77.16,76.91,35.17,34.79,34.76,32.49,31.73,31.67$. ESI-HRMS $(\mathrm{m} / \mathrm{z})$ : calculated for $\mathrm{C}_{77} \mathrm{H}_{59} \mathrm{O}^{+}\left([M+\mathrm{H}]^{+}\right)$: 999.4560, found: 999.4536 .

9-(4-bromobiphenylenylethynyl)-10-phenylethynylanthracene (S3)

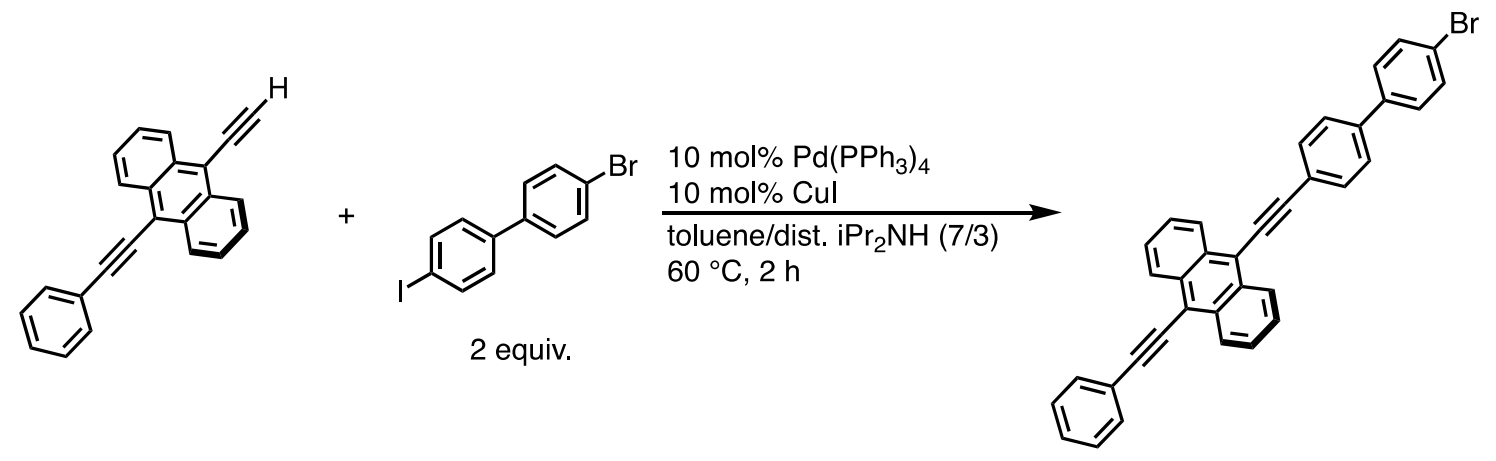


To a mixture of 4-bromo-4'-iodobiphenyl (359 mg, $1.0 \mathrm{mmol}), \mathrm{Pd}\left(\mathrm{PPh}_{3}\right)_{4}(58 \mathrm{mg}, 0.05 \mathrm{mmol}, 10 \mathrm{~mol} \%$ ), and $\mathrm{CuI}$ (4.8 mg, $0.05 \mathrm{mmol}, 10 \mathrm{~mol} \%$ ) in toluene $/ i \operatorname{Pr}_{2} \mathrm{NH}(7 / 3 \mathrm{~mL})$, was added 9-ethynyl-10phenylehynylanthracene $(151 \mathrm{mg}, 0.50 \mathrm{mmol})$. After stirring at $60{ }^{\circ} \mathrm{C}$ for $3 \mathrm{~h}$, the reaction mixture was poured onto water and extracted with $\mathrm{CH}_{2} \mathrm{Cl}_{2}$. Organic phase was washed with brine and dried over anhydrous $\mathrm{Na}_{2} \mathrm{SO}_{4}$. The crude mixture was purified with silica gel column chromatography (eluent: $\mathrm{CH}_{2} \mathrm{Cl}_{2} / n$-hexane $\left.=1 / 9\right)$. Recrystallization from $\mathrm{MeOH}$ gave $\mathbf{S 3}$ (258 mg, $\left.0.48 \mathrm{mmol}, 96 \%\right)$.

${ }^{1} \mathrm{H}$ NMR $\left(\mathrm{CDCl}_{3}, 298 \mathrm{~K}\right) \delta / \mathrm{ppm}=8.72-8.67(\mathrm{~m}, 4 \mathrm{H}), 7.83(\mathrm{~d}, J=8.4 \mathrm{~Hz}, 2 \mathrm{H}), 7.77(\mathrm{dd}, J=8.1,1.5 \mathrm{~Hz}$, 2H), $7.67-7.61(\mathrm{~m}, 6 \mathrm{H}), 7.59(\mathrm{~d}, J=8.5 \mathrm{~Hz}, 2 \mathrm{H}), 7.51(\mathrm{~d}, J=8.5 \mathrm{~Hz}, 2 \mathrm{H}), 7.48-7.39(\mathrm{~m}, 3 \mathrm{H}) ;{ }^{13} \mathrm{C} \mathrm{NMR}$ $\left(\mathrm{CDCl}_{3}, 298 \mathrm{~K}\right) \delta / \mathrm{ppm}=140.31,139.39,132.39,132.28,132.22,131.87,128.91,128.80,128.75,127.48$, $127.38,127.20,127.06,127.02,123.56,122.90,122.26,118.80,118.49,102.68,102.30,87.70,86.62$, $77.41,77.16,76.91$.

9-[4-(4,4,5,5-tetramethyl-1,3,2-dioxaborolan-2-yl)biphenylenylethynyl]-10-phenylethynylanthracene (S5)
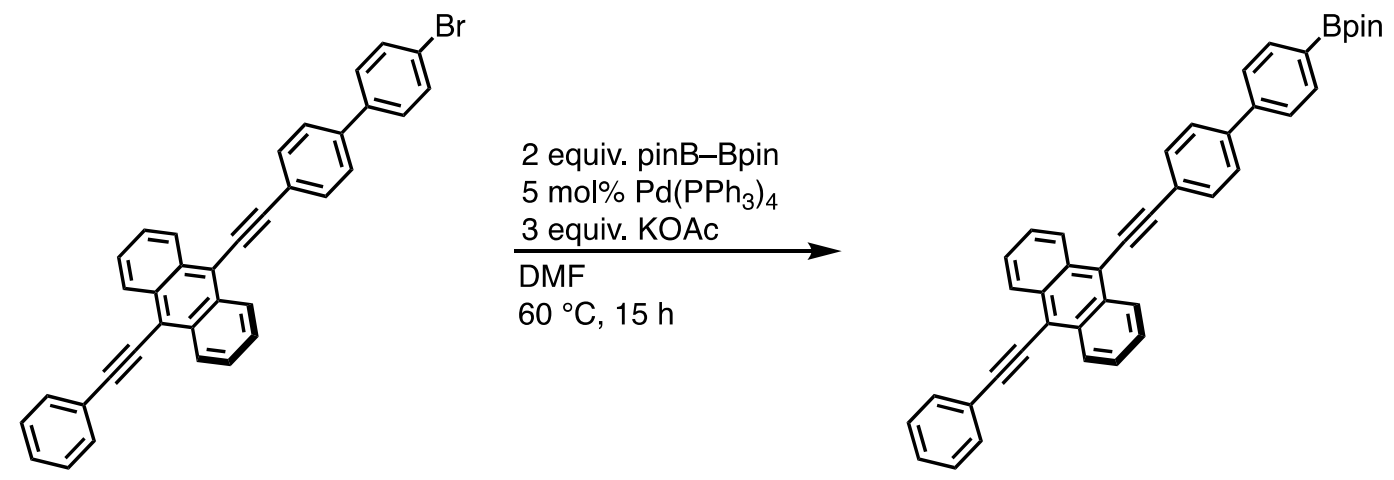

A mixture of $\mathbf{S 3}$ (160 mg, $0.30 \mathrm{mmol}), \mathrm{B}_{2}$ (pin) $)_{2}\left(152 \mathrm{mg}, 0.60 \mathrm{mmol}, 2\right.$ equiv.), $\mathrm{Pd}\left(\mathrm{PPh}_{3}\right)_{4}(17 \mathrm{mg}, 15 \mu \mathrm{mol}$, $5 \mathrm{~mol} \%$ ), and KOAc ( $88 \mathrm{mg}, 0.90 \mathrm{mmol}, 3$ equiv.) in $30 \mathrm{~mL}$ of DMF was stirred at $80{ }^{\circ} \mathrm{C}$ for $15 \mathrm{~h}$. The reaction mixture was extracted with $\mathrm{CH}_{2} \mathrm{Cl}_{2}$ and washed with water and brine. Organic mixture was separated and dried over anhydrous $\mathrm{Na}_{2} \mathrm{SO}_{4}$. Recrystallization from $\mathrm{MeOH}$ gave $\mathbf{S 5}$ (136 mg, $0.23 \mathrm{mmol}$, $76 \%$ ).

${ }^{1} \mathrm{H}$ NMR $\left(\mathrm{CDCl}_{3}, 298 \mathrm{~K}\right) \delta / \mathrm{ppm}=8.75-8.68(\mathrm{~m}, 4 \mathrm{H}), 7.93(\mathrm{~d}, J=8.2 \mathrm{~Hz}, 2 \mathrm{H}), 7.86(\mathrm{~d}, J=8.2 \mathrm{~Hz}, 2 \mathrm{H})$, $7.79(\mathrm{dd}, J=7.1,1.5 \mathrm{~Hz}, 2 \mathrm{H}), 7.73(\mathrm{~d}, J=8.2 \mathrm{~Hz}, 2 \mathrm{H}), 7.70-7.64(\mathrm{~m}, 6 \mathrm{H}), 7.49-7.42(\mathrm{~m}, 3 \mathrm{H}) ;{ }^{13} \mathrm{C} \mathrm{NMR}$ $\left(\mathrm{CDCl}_{3}, 298 \mathrm{~K}\right) \delta / \mathrm{ppm}=143.06,141.37,135.55,132.28,131.86,128.87,128.74,127.49,127.44,127.03$, $127.00,126.51,123.58,122.76,118.69,118.62,102.62$, 102.53, 87.56, 86.66, 84.06, 77.41, 77.16, 76.91, 25.05 . 
4-[4-(10-phenylethynylanthracen-9-ylethynylphenyl)-phenyl]-5-(10-phenylethynylanthracen-9ylethynyl)-2,7-di-tert-butyl-9,9-dimethylxanthene (2ph)
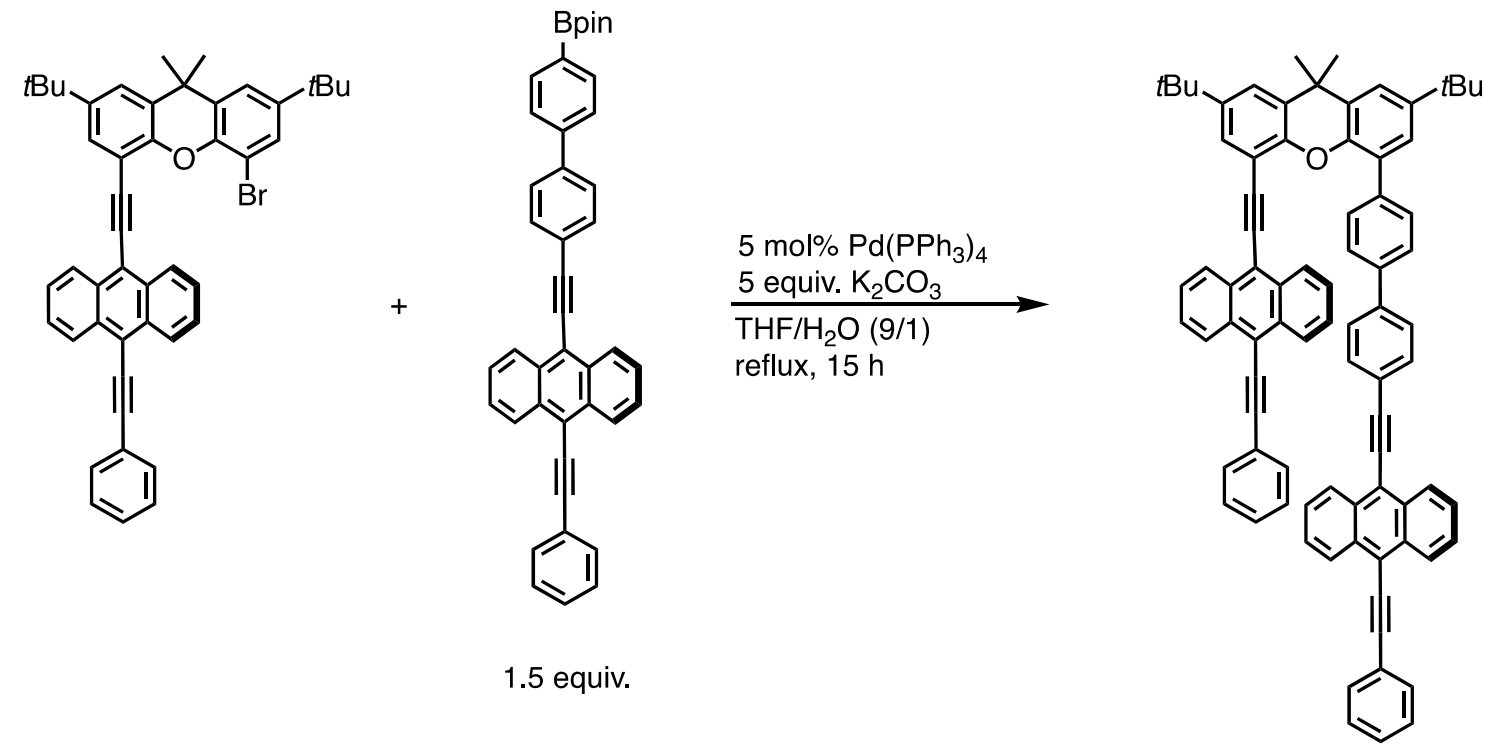

A mixture of S1 (30 mg, $43 \mu \mathrm{mol}), \mathbf{S 5}$ (49 mg, $64 \mu \mathrm{mol}, 1.5$ equiv.), $\mathrm{Pd}\left(\mathrm{PPh}_{3}\right)_{4}(2.5 \mathrm{mg}, 22 \mu \mathrm{mol}, 5 \mathrm{~mol} \%$ ), and $\mathrm{K}_{2} \mathrm{CO}_{3}$ (29 mg, $0.22 \mathrm{mmol}, 5$ equiv.) in THF/water $(9 / 1 \mathrm{~mL})$ was heated to reflux for $15 \mathrm{~h}$. The reaction mixture was extracted with $\mathrm{CH}_{2} \mathrm{Cl}_{2}$ and washed with water and brine. Organic mixture was separated and dried over anhydrous $\mathrm{Na}_{2} \mathrm{SO}_{4}$. The crude mixture was purified with silica gel column chromatography (eluent: $\mathrm{CH}_{2} \mathrm{Cl}_{2}$ /hexanes). Recrystallization from $\mathrm{MeOH}$ gave $\mathbf{2 p h}(40 \mathrm{mg}, 37 \mu \mathrm{mol}, 86 \%$ ).

${ }^{1} \mathrm{H}$ NMR $\left(\mathrm{CDCl}_{3}, 298 \mathrm{~K}\right) \delta / \mathrm{ppm}=8.70(\mathrm{~d}, J=8.6 \mathrm{~Hz}, 2 \mathrm{H}), 8.59(\mathrm{~d}, J=8.7 \mathrm{~Hz}, 2 \mathrm{H}), 8.56(\mathrm{~d}, J=8.7 \mathrm{~Hz}$, $2 \mathrm{H}), 8.48(\mathrm{~d}, J=8.6 \mathrm{~Hz}, 2 \mathrm{H}), 7.81(\mathrm{~d}, J=6.7 \mathrm{~Hz}, 2 \mathrm{H}), 7.70(\mathrm{~d}, J=8.2 \mathrm{~Hz}, 2 \mathrm{H}), 7.63(\mathrm{t}, J=7.6 \mathrm{~Hz}, 2 \mathrm{H})$, $7.60-7.41(\mathrm{~m}, 16 \mathrm{H}), 7.30(\mathrm{~d}, J=2.3 \mathrm{~Hz}, 1 \mathrm{H}), 6.83(\mathrm{~d}, J=8.1 \mathrm{~Hz}, 2 \mathrm{H}), 6.68(\mathrm{t}, J=7.3 \mathrm{~Hz}, 1 \mathrm{H}), 6.63(\mathrm{t}, J$ $=7.3 \mathrm{~Hz}, 2 \mathrm{H}), 6.47(\mathrm{~d}, J=8.2 \mathrm{~Hz}, 2 \mathrm{H}), 1.78(\mathrm{~s}, 6 \mathrm{H}), 1.40(\mathrm{~s}, 9 \mathrm{H}), 1.38(\mathrm{~s}, 9 \mathrm{H}) ;{ }^{13} \mathrm{C} \mathrm{NMR}\left(\mathrm{CDCl}_{3}, 298 \mathrm{~K}\right.$, $171027-01 \mathrm{C}) \delta / \mathrm{ppm}=149.58,146.02,145.63,145.58,139.78,137.64,137.36,132.27,132.20,132.17$, $131.87,131.70,131.50,130.28,130.26,130.17,128.88,128.85,128.77,128.33,128.13,128.09,127.58$, $127.53,127.26,127.21,126.94,126.81,126.74,126.72,126.36,126.09,125.92,123.75,123.68,123.18$, $122.11,121.64,119.18,119.11,118.64,118.13,111.21,103.40,102.81,102.43,98.83,90.06,87.04,86.83$, 86.44, 77.41, 77.16, 76.91, 35.19, 34.77, 34.75, 32.43, 31.73, 31.67. ESI-HRMS $(\mathrm{m} / \mathrm{z})$ : calculated for $\mathrm{C}_{83} \mathrm{H}_{63} \mathrm{O}^{+}\left([M+\mathrm{H}]^{+}\right): 1075.4873$, found: 1075.4867 . 


\section{Kinetic fitting of the fsTA and TRF data}

Prior to kinetic analysis, the fsTA data were background/scatter-subtracted and chirp-corrected, and the similar data sets were spectrally merged (Surface Xplorer 4, Ultrafast Systems, LLC). The kinetic analysis was performed using home written programs in MATLAB and was based on a global fit to selected wavelength/frequency kinetics. The time-resolution is given as $\mathrm{w}=300 \mathrm{fs}$ (full width at half maximum, FWHM); the assumption of a uniform instrument response across the frequency domain and a fixed time-zero (t0) are implicit in global analysis. Kinetic data from multiple different wavelengths/frequencies were fit using the global analysis described below. Each wavelength/frequency was given an initial amplitude that is representative of the spectral intensity at time t0 and varied independently to fit the data. The time/rate constants and t0 are shared between the various kinetic data and are varied globally across the kinetic data in order to fit the models described in the text. We globally fit the dataset to a specified kinetic model and use the resultant populations to deconvolute the dataset and reconstruct species-associated spectra. The MATLAB program numerically the solves the differential equations through matrix methods, then convolutes the solutions with a Gaussian instrument response function with width w before employing a least-squares fitting using a Levenberg-Marquardt or Simplex method to find the parameters which result in matches to the kinetic data. Once the fit parameters are established, they are fed directly into the differential equations, which were solved for the populations of the states in model-i.e., A(t), B(t), and $\mathrm{C}(\mathrm{t})$, etc. Finally, the raw data matrix (with all the raw data) is deconvoluted with the populations as functions of time to produce the spectra associated with each species. 


\section{Steady state absorbance and emission}
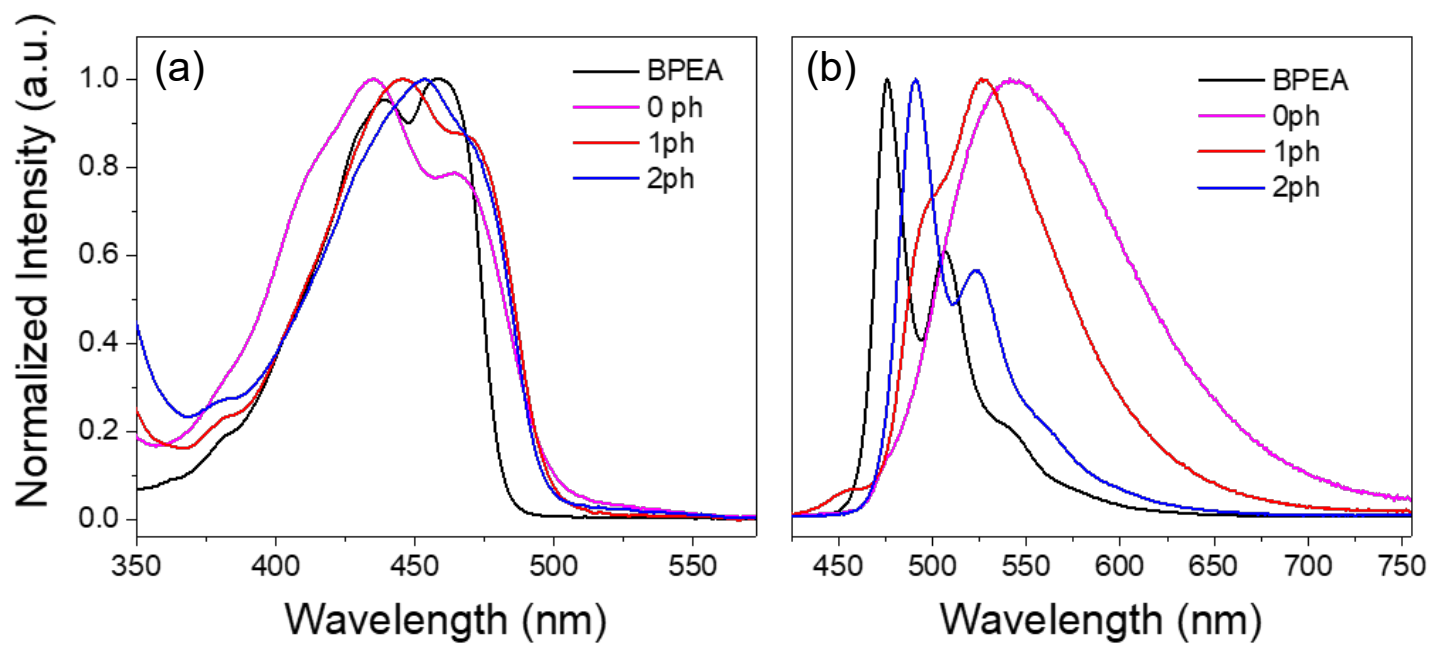

Figure S1. (a) steady state absorbance and (b) emission spectra of BPEA monomer and dimers in Tol.

Table S1. The peak positions, $\mathrm{S}_{1}(E)$, and FLQY of BPEA monomer and dimers in toluene.

\begin{tabular}{ccccc}
\hline & $0-0(\mathrm{~nm})$ & $0-1(\mathrm{~nm})$ & $\mathrm{S}_{1}(E)(\mathrm{eV})$ & $\Phi_{\mathrm{fl}}(\%)$ \\
\hline BPEA & 458 & 439 & 2.64 & $100 \pm 2$ \\
0ph & 465 & 435 & 2.53 & $44 \pm 3$ \\
1ph & 471 & 447 & 2.55 & $87 \pm 3$ \\
2ph & 471 & 454 & 2.57 & $90 \pm 5$ \\
\hline
\end{tabular}
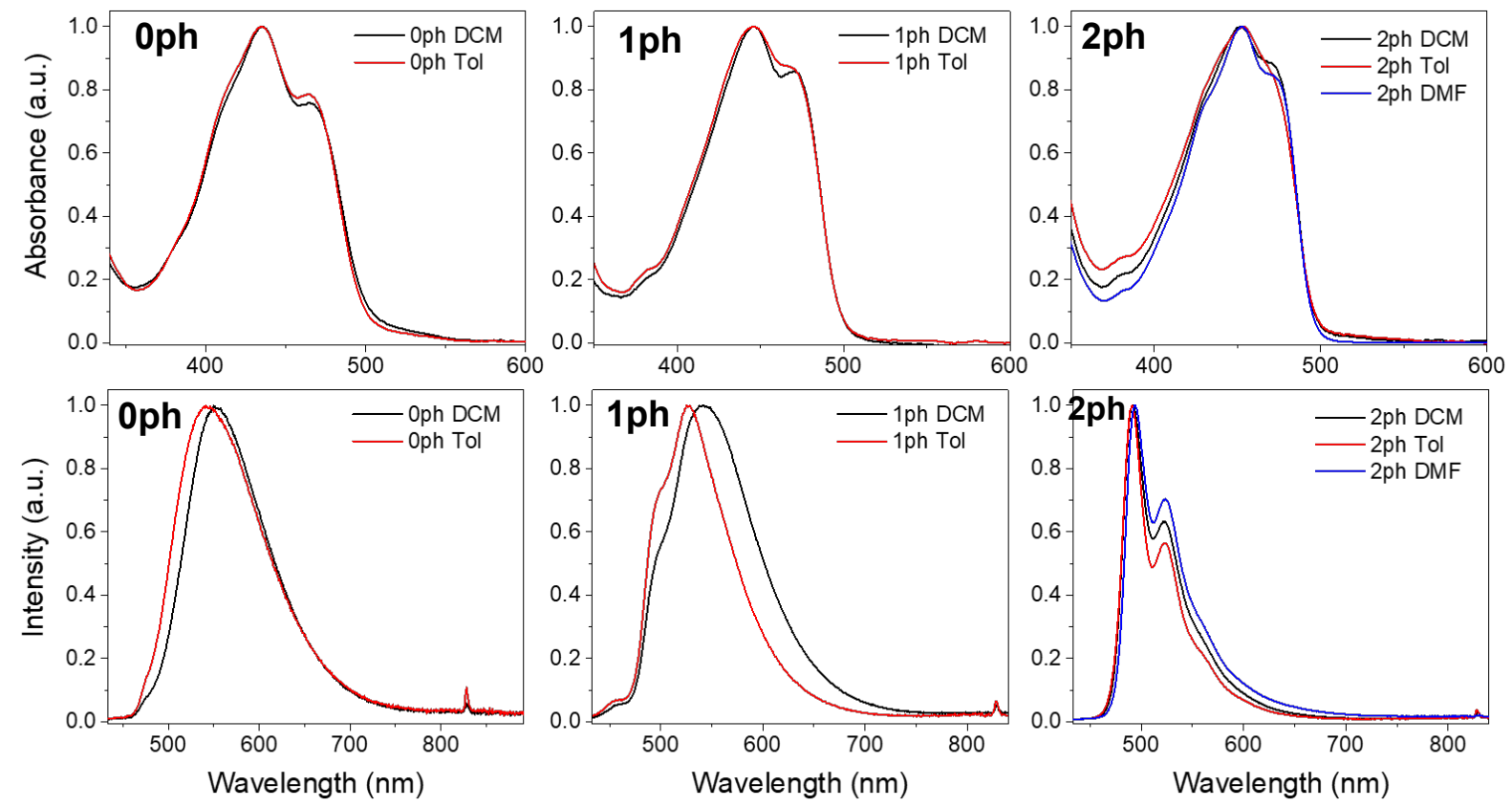

Figure S2. (Top) steady state absorbance and (Bottom) emission spectra of BPEA dimers in different solvents. 


\section{Additional TRF data}
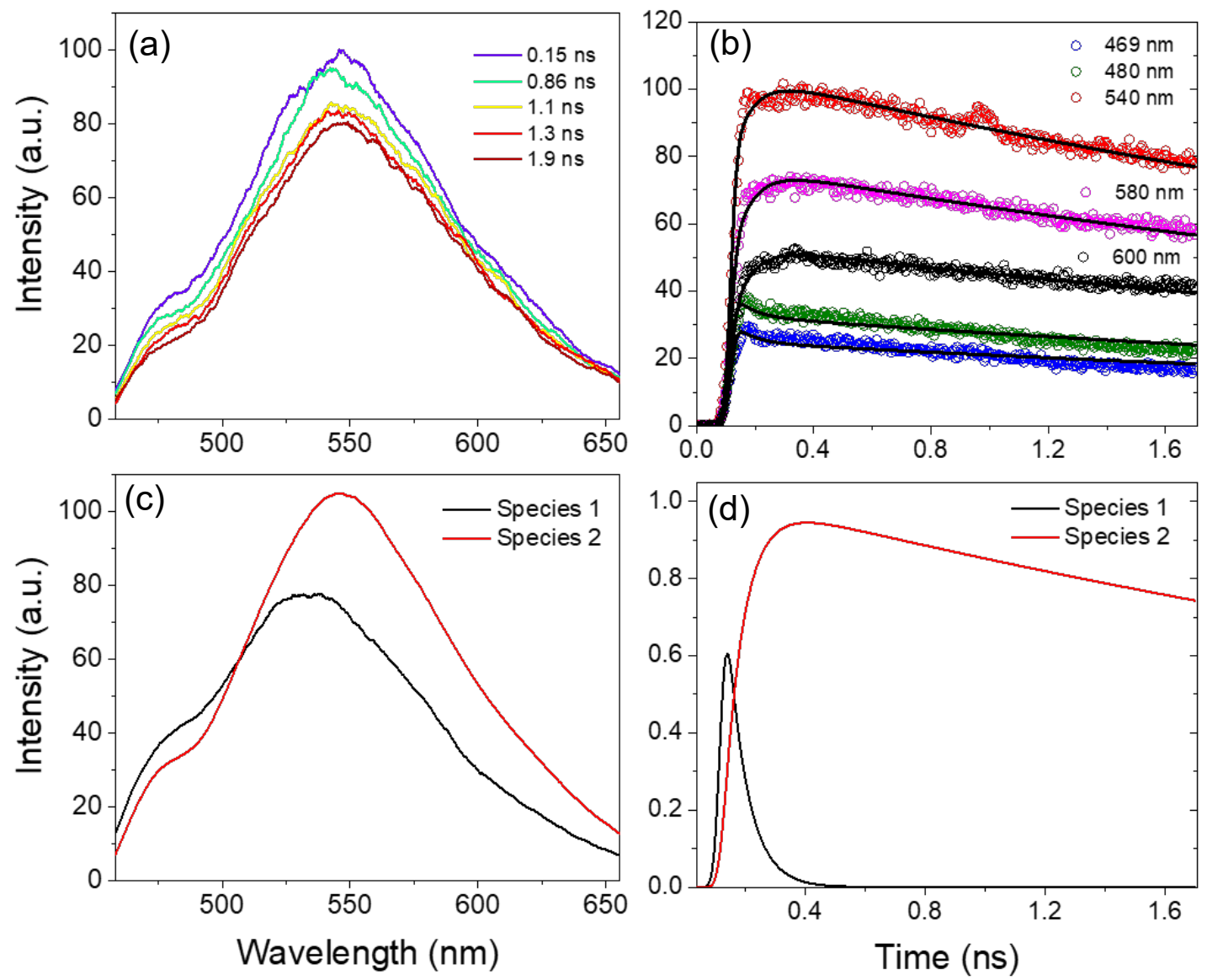

Figure S3. Global analysis of the (a) TRF data for 0ph in DCM for the $2 \mathrm{~ns}$ time window. (b) Wavelength kinetic fits, (c) evolution-associated spectra and (d) population $v s$. time fits to a sequential $\mathrm{A} \rightarrow \mathrm{B} \rightarrow$ GS model.
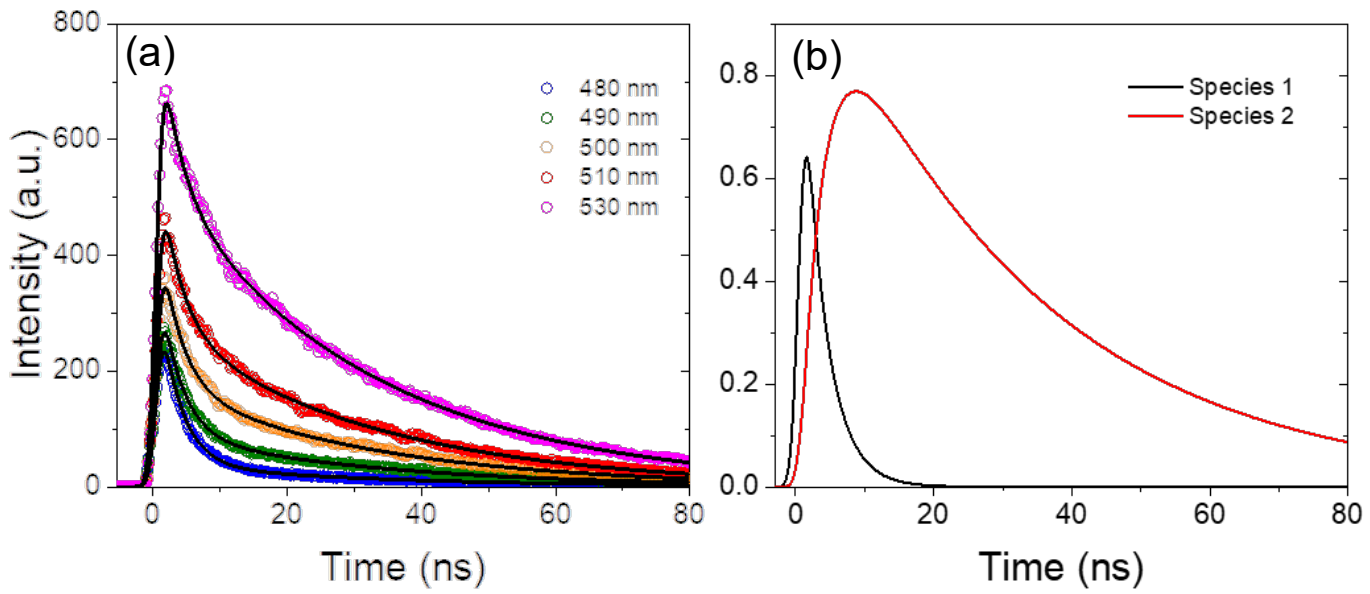

Figure S4. Global analysis of the TRF data for $\mathbf{0 p h}$ in DCM for the $100 \mathrm{~ns}$ time window. (a) Kinetic fits to a sequential $\mathrm{A} \rightarrow \mathrm{B} \rightarrow \mathrm{GS}$ model and (b) population $v s$. time fit. 

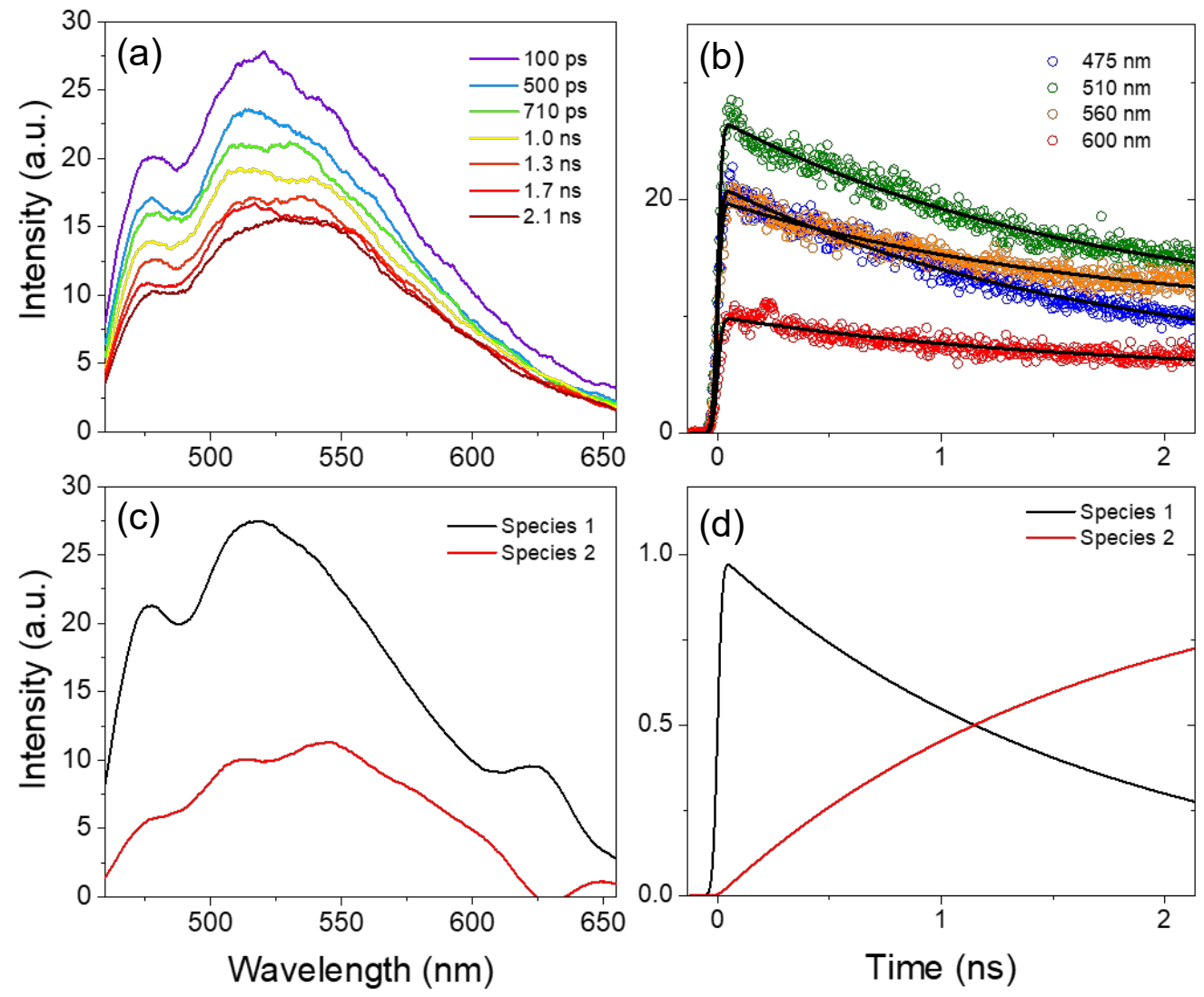

Figure S5. Global analysis of the (a) TRF data for $\mathbf{0 p h}$ in Tol for the 2 ns time window. (b) Wavelength kinetic fits, (c) evolution-associated spectra and (d) population $v s$. time fits to a sequential $\mathrm{A} \rightarrow \mathrm{B} \rightarrow$ GS model. 

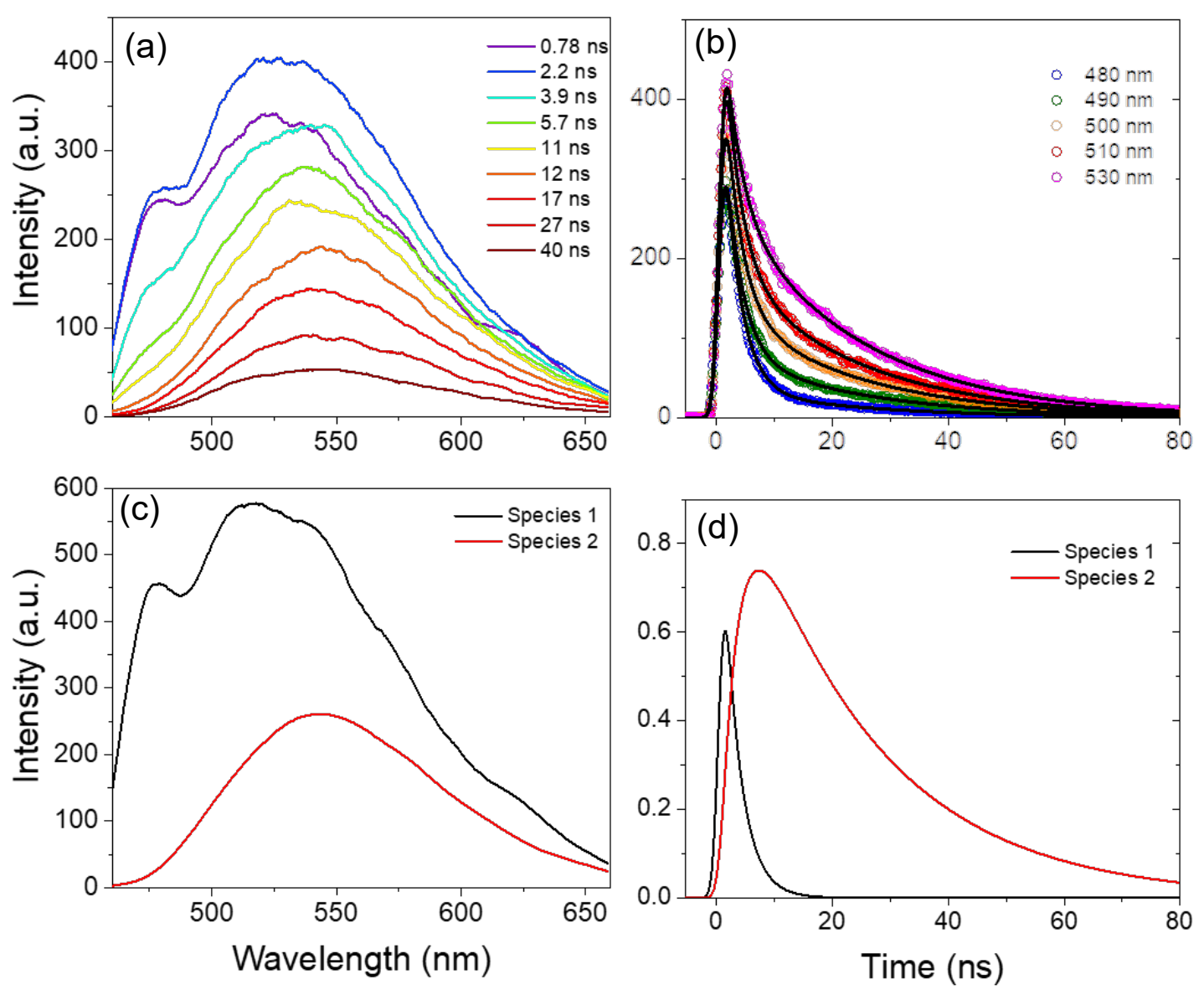

Figure S6. Global analysis of the (a) TRF data for $\mathbf{0 p h}$ in Tol for the $100 \mathrm{~ns}$ time window. (b) Wavelength kinetic fits, (c) evolution-associated spectra and (d) population vs. time fits to a sequential $\mathrm{A} \rightarrow \mathrm{B} \rightarrow$ GS model.
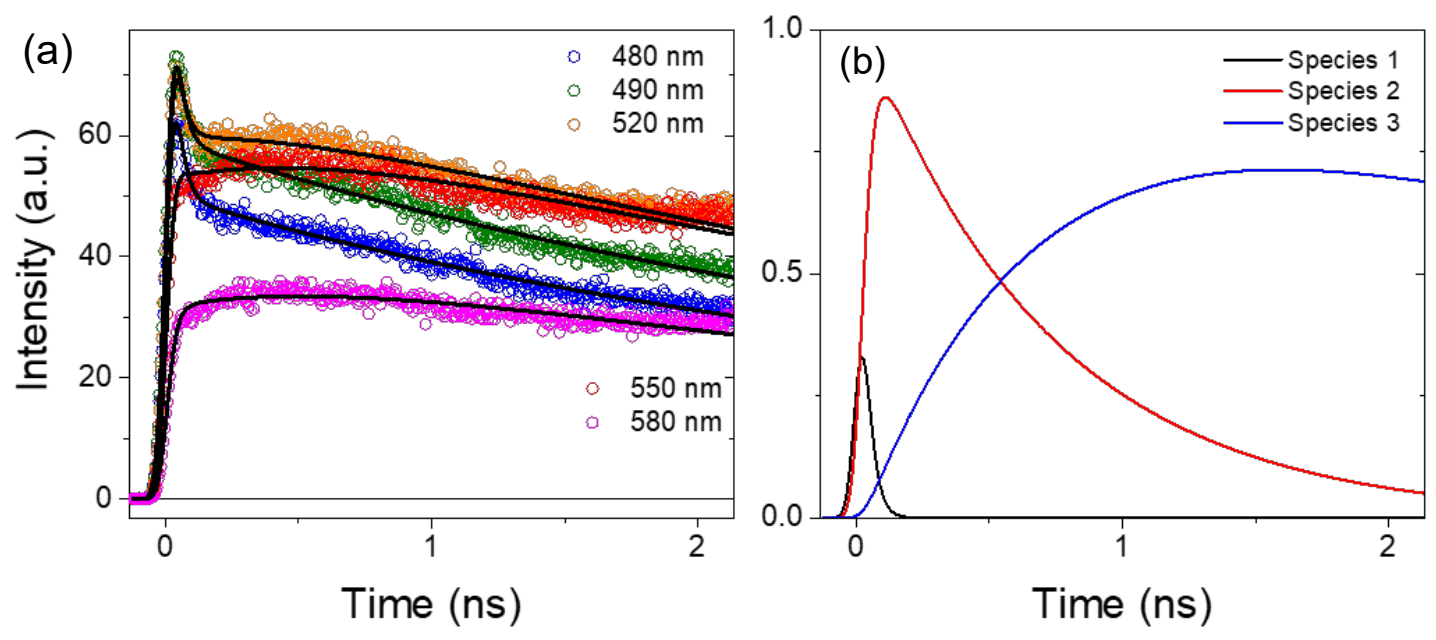

Figure S7. Global analysis of the TRF data for 1ph in DCM for the 2 ns time window. (a) Kinetic fits to a sequential $\mathrm{A} \rightarrow \mathrm{B} \rightarrow \mathrm{C} \rightarrow \mathrm{GS}$ model and (b) population vs. time fit. 

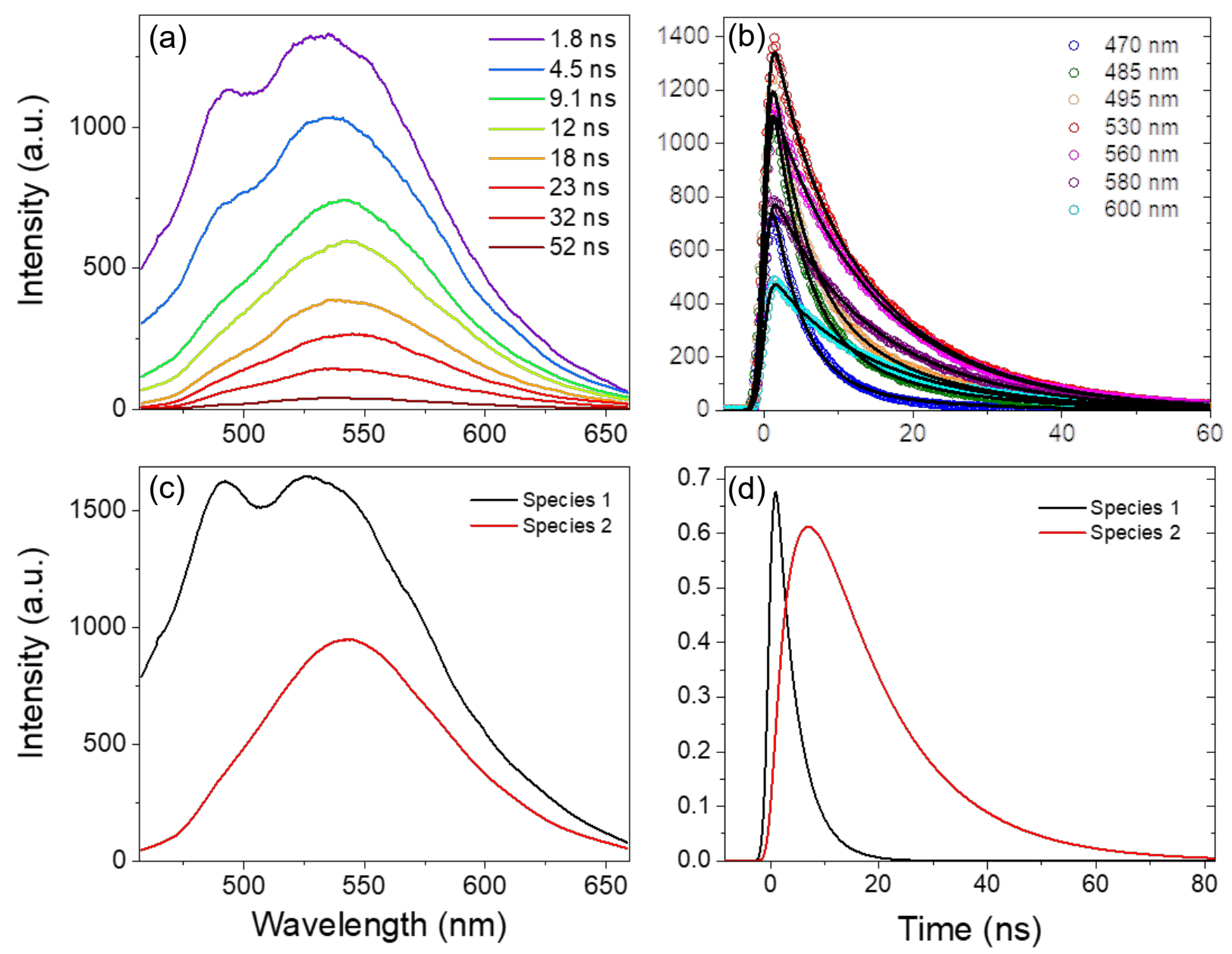

Figure S8. Global analysis of the (a) TRF data for 1ph in DCM for the 100 ns time window. (b) Wavelength kinetic fits, (c) evolution-associated spectra and (d) population vs. time fits to a sequential $\mathrm{A} \rightarrow \mathrm{B} \rightarrow$ GS model. 

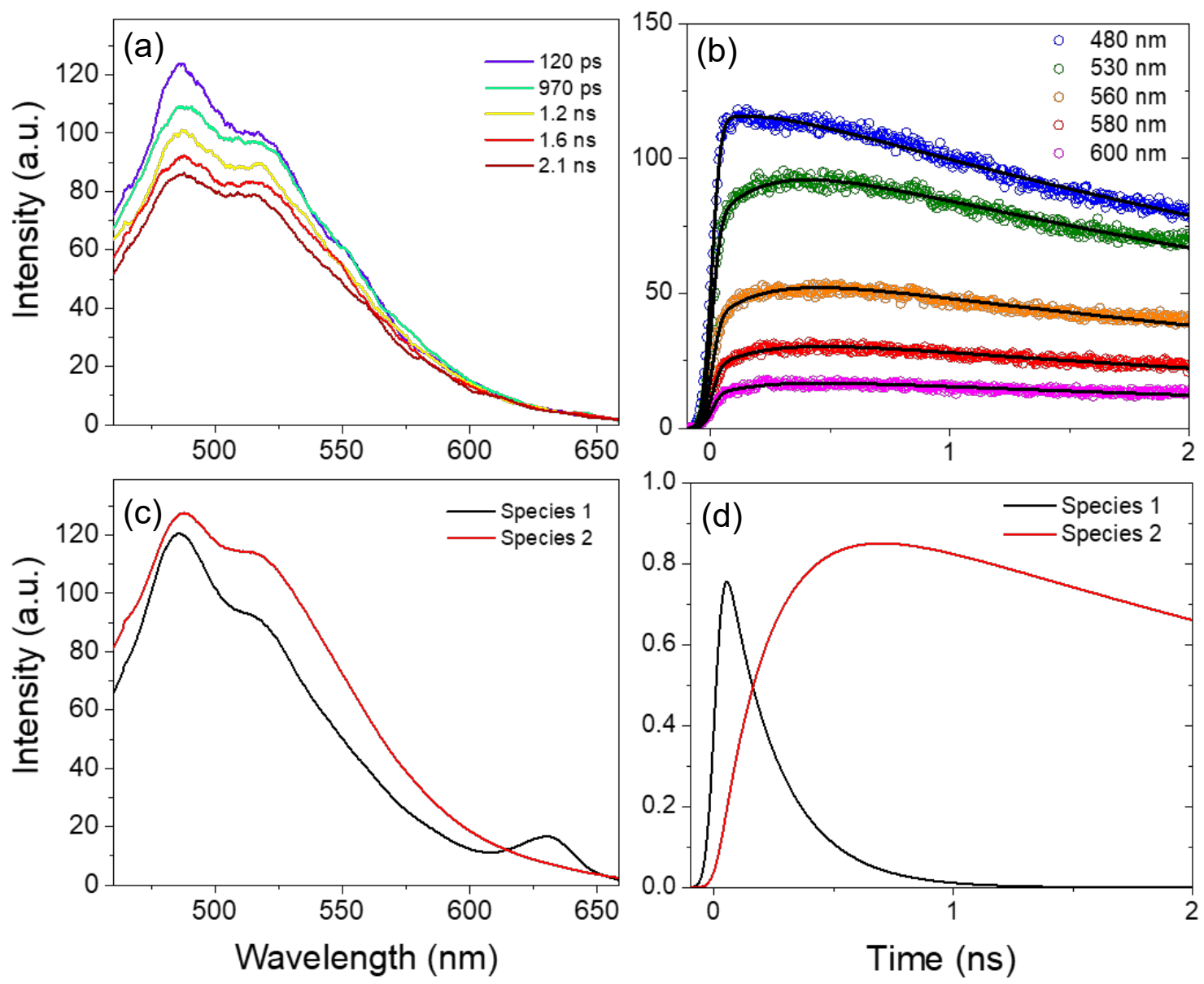

Figure S9. Global analysis of the (a) TRF data for 1 ph in Tol for the 2 ns time window. (b) Wavelength kinetic fits, (c) evolution-associated spectra and (d) population vs. time fits to a sequential $\mathrm{A} \rightarrow \mathrm{B} \rightarrow$ GS model. 

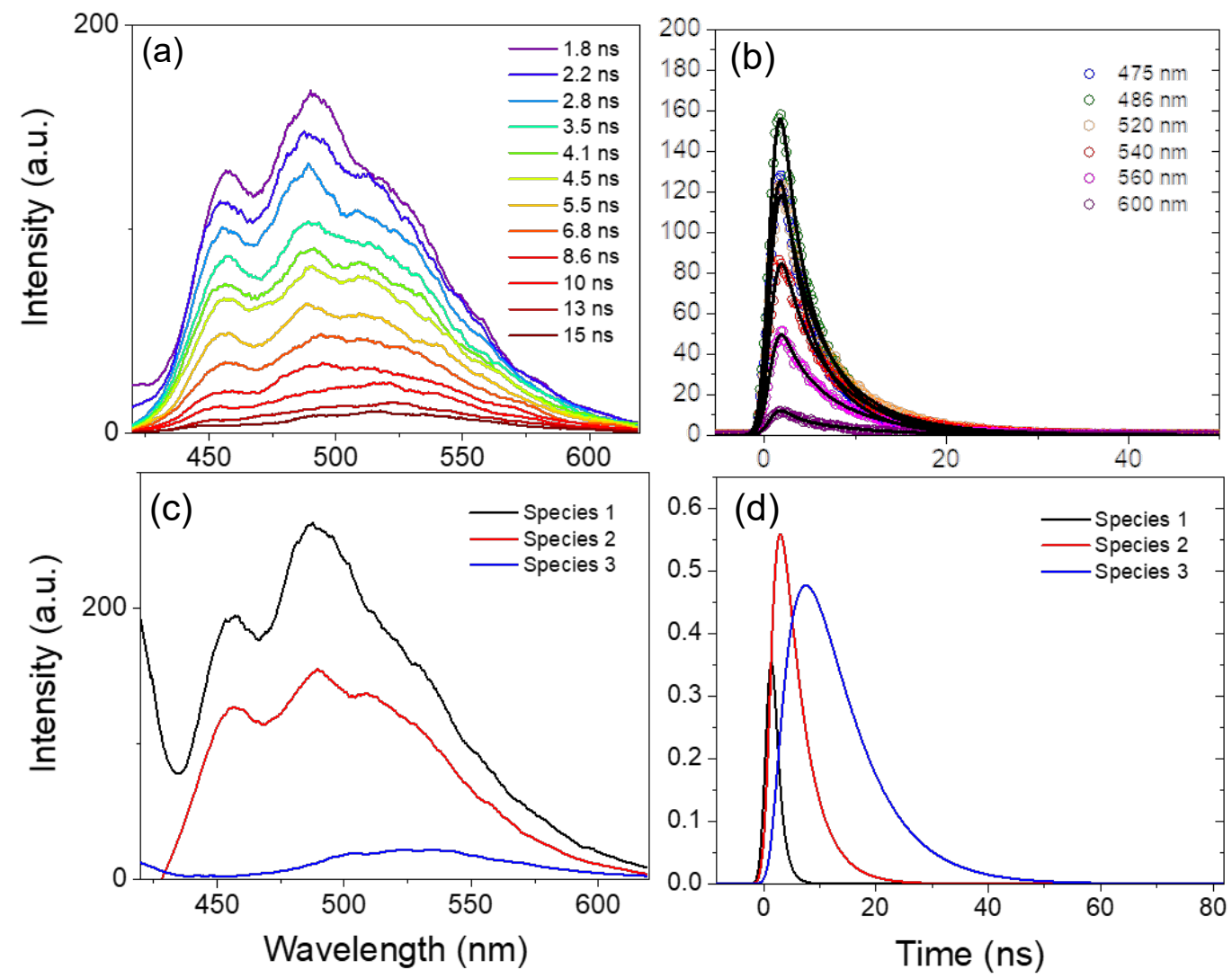

Figure S10. Global analysis of the (a) TRF data for $\mathbf{1 p h}$ in Tol for the $100 \mathrm{~ns}$ time window. (b) Wavelength kinetic fits, (c) evolution-associated spectra and (d) population $v s$. time fits to a sequential $\mathrm{A} \rightarrow \mathrm{B} \rightarrow \mathrm{C} \rightarrow \mathrm{GS}$ model.
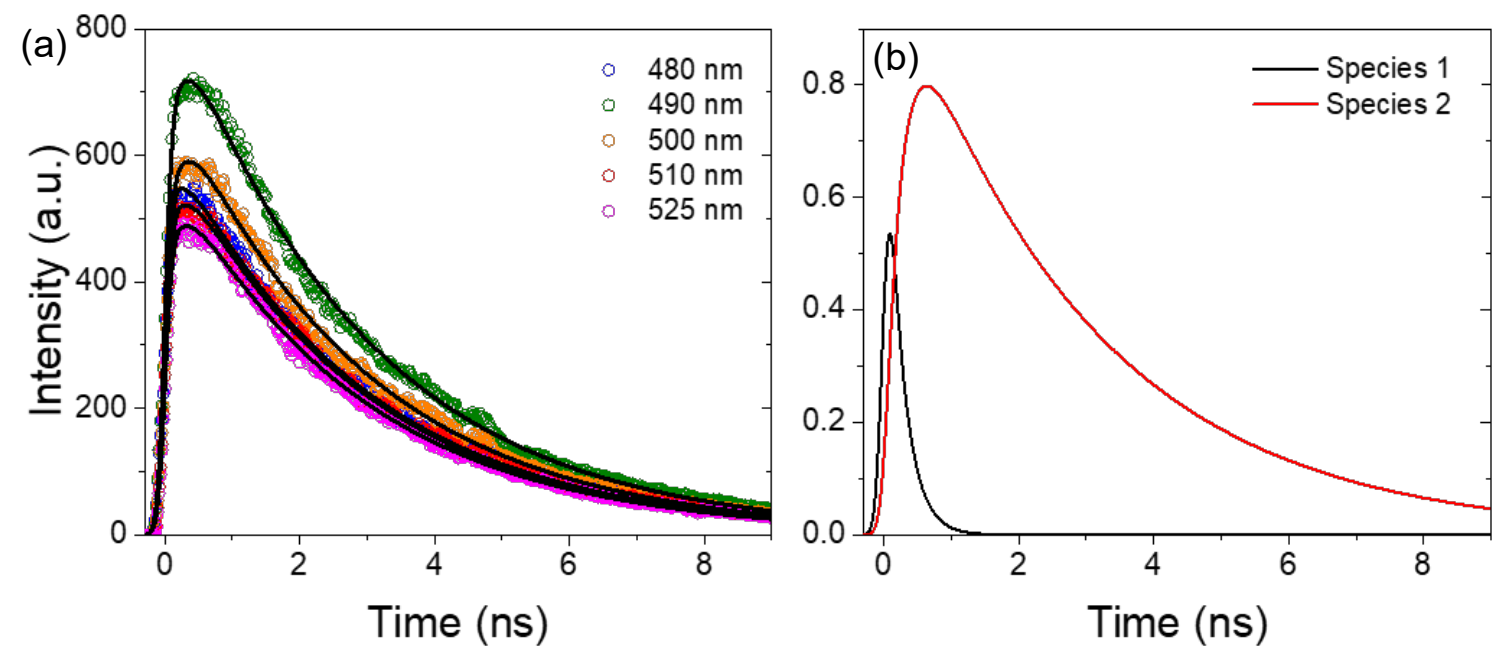

Figure S11. Global analysis of the TRF data for $\mathbf{2 p h}$ in DCM for the $10 \mathrm{~ns}$ time window. (a) Kinetic fits to a sequential $\mathrm{A} \rightarrow \mathrm{B} \rightarrow \mathrm{C} \rightarrow$ GS model and (b) population vs. time fit. 

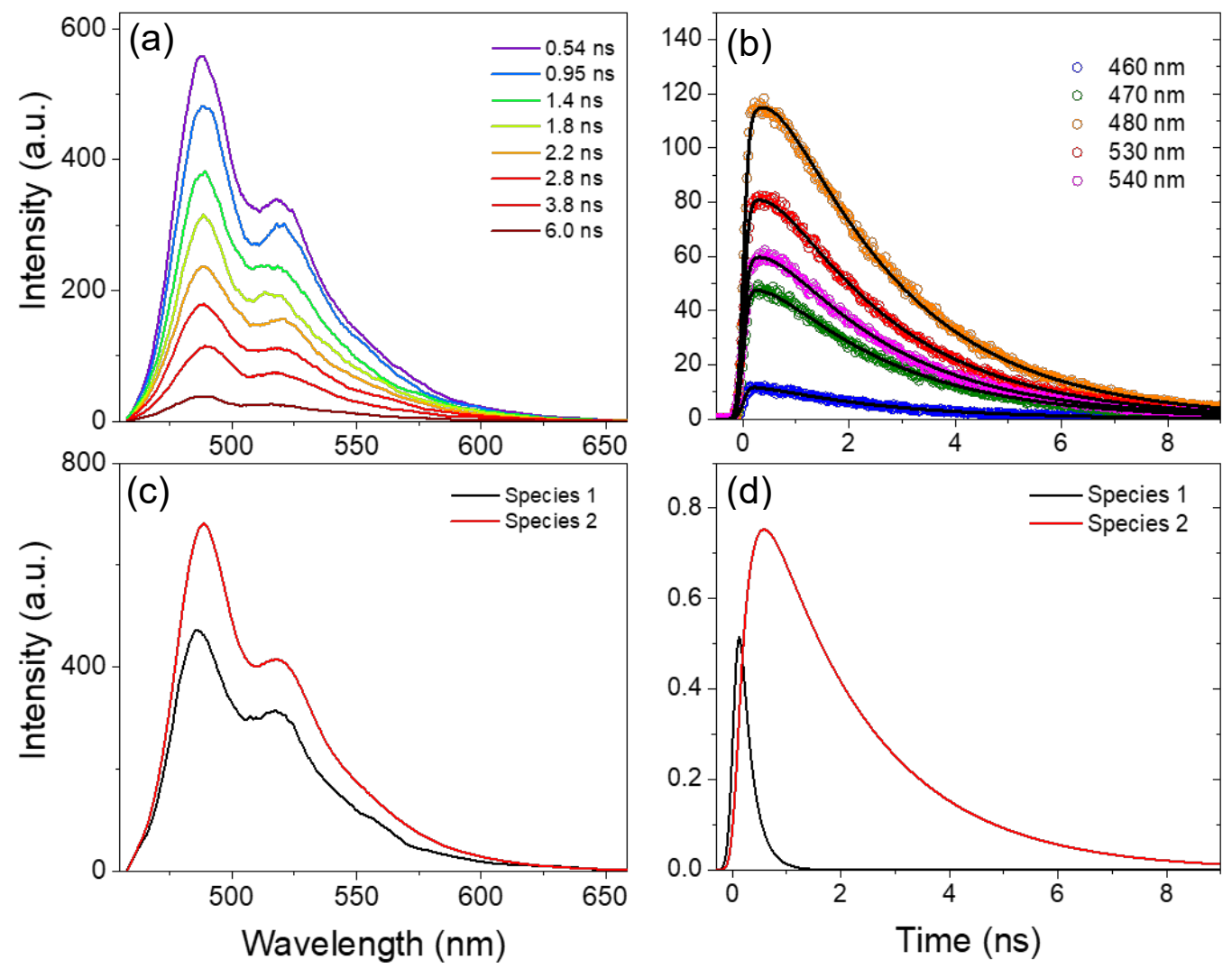

Figure S12. Global analysis of the (a) TRF data for $\mathbf{2 p h}$ in Tol for the $10 \mathrm{~ns}$ time window. (b) Wavelength kinetic fits, (c) evolution-associated spectra and (d) population vs. time fits to a sequential $\mathrm{A} \rightarrow \mathrm{B} \rightarrow$ GS model. 


\section{Additional TA data}
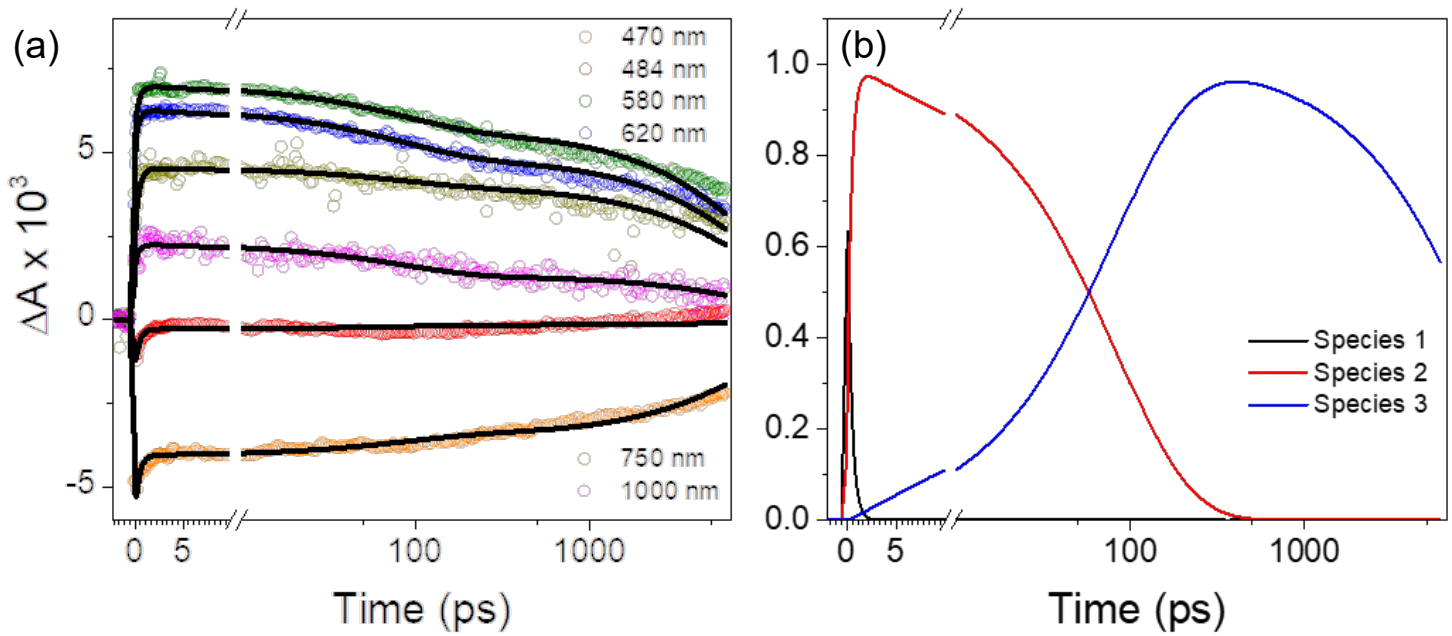

Figure S13. Global analysis of the fsTA data for $\mathbf{0 p h}$ in DCM. (a) Kinetic fits to a sequential $\mathrm{A} \rightarrow \mathrm{B} \rightarrow \mathrm{C} \rightarrow \mathrm{GS}$ model and (b) population $v s$. time fit.
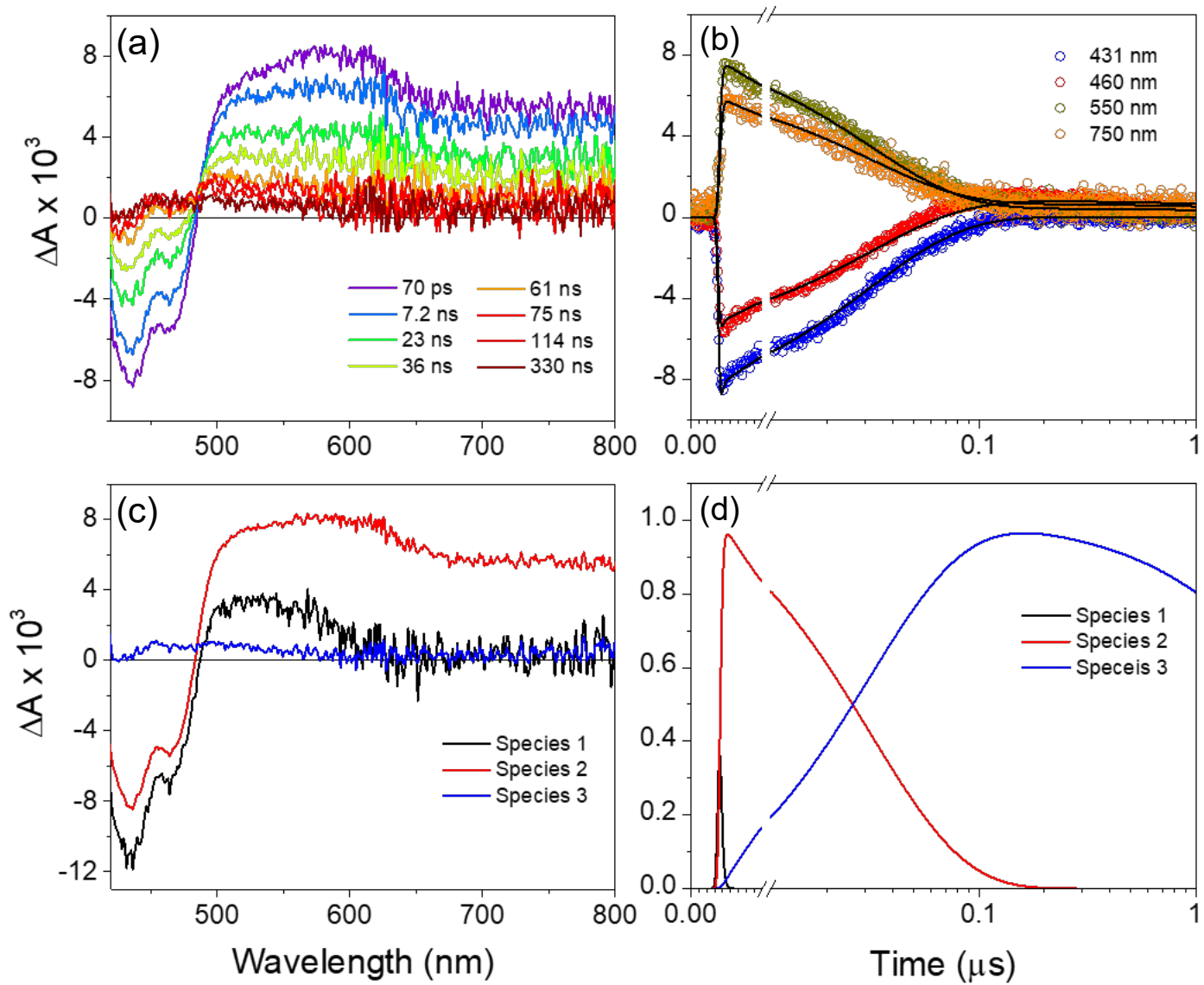

Figure S14. Global analysis of the (a) fsTA data for 0ph in DCM for the time window of $1 \mu$ s. (b) Wavelength kinetic fits, (c) evolution-associated spectra and (d) population vs. time fits to a sequential $\mathrm{A} \rightarrow \mathrm{B} \rightarrow \mathrm{GS}$ model. Here, species 3 is assigned to the triplet excited state formed by intersystem crossing. 

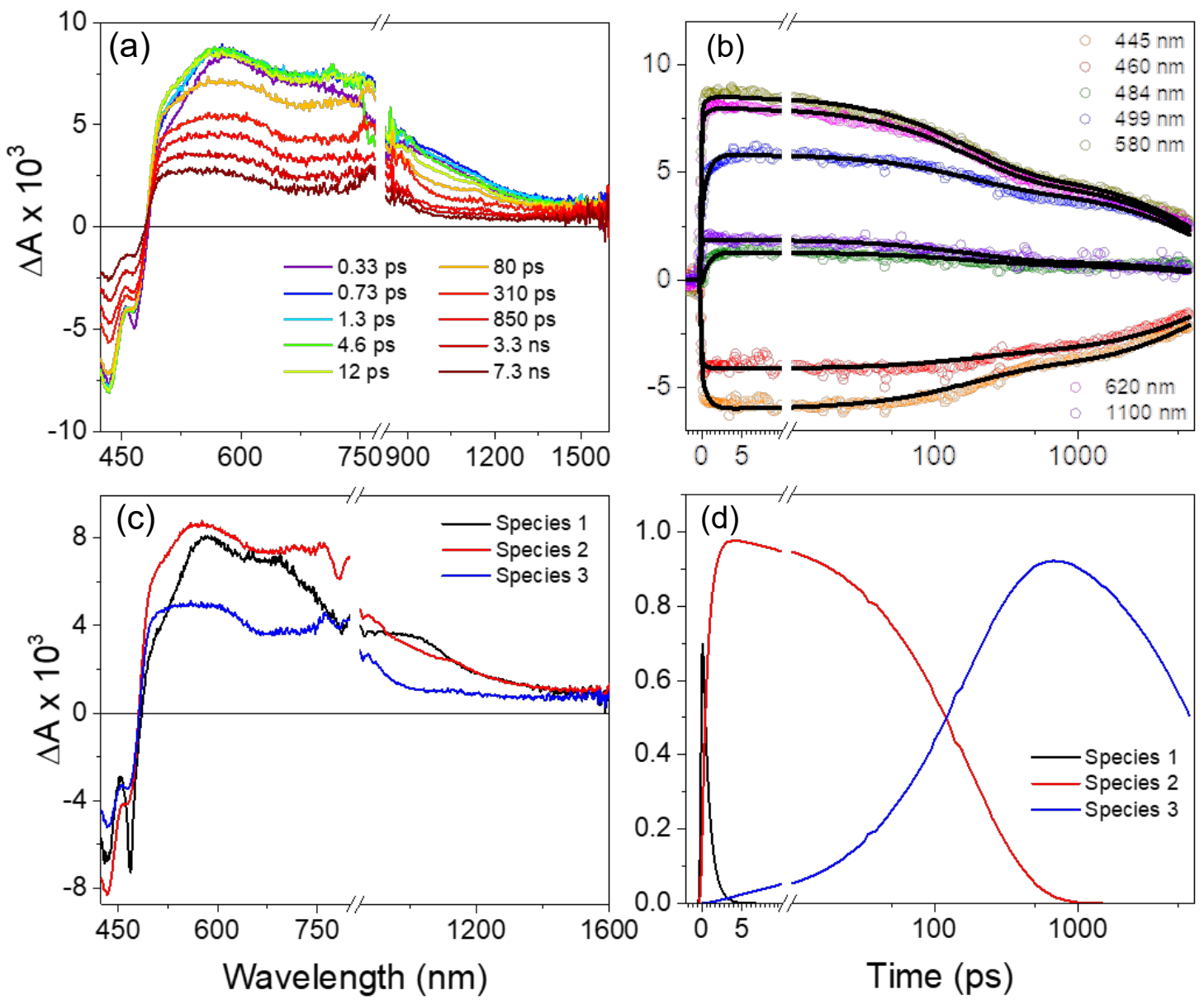

Figure S15. Global analysis of the (a) fsTA data for 0 ph in Tol for the time window of 7.4 ns. (b) Wavelength kinetic fits, (c) evolution-associated spectra and (d) population vs. time fits to a sequential $\mathrm{A} \rightarrow \mathrm{B} \rightarrow \mathrm{GS}$ model. 

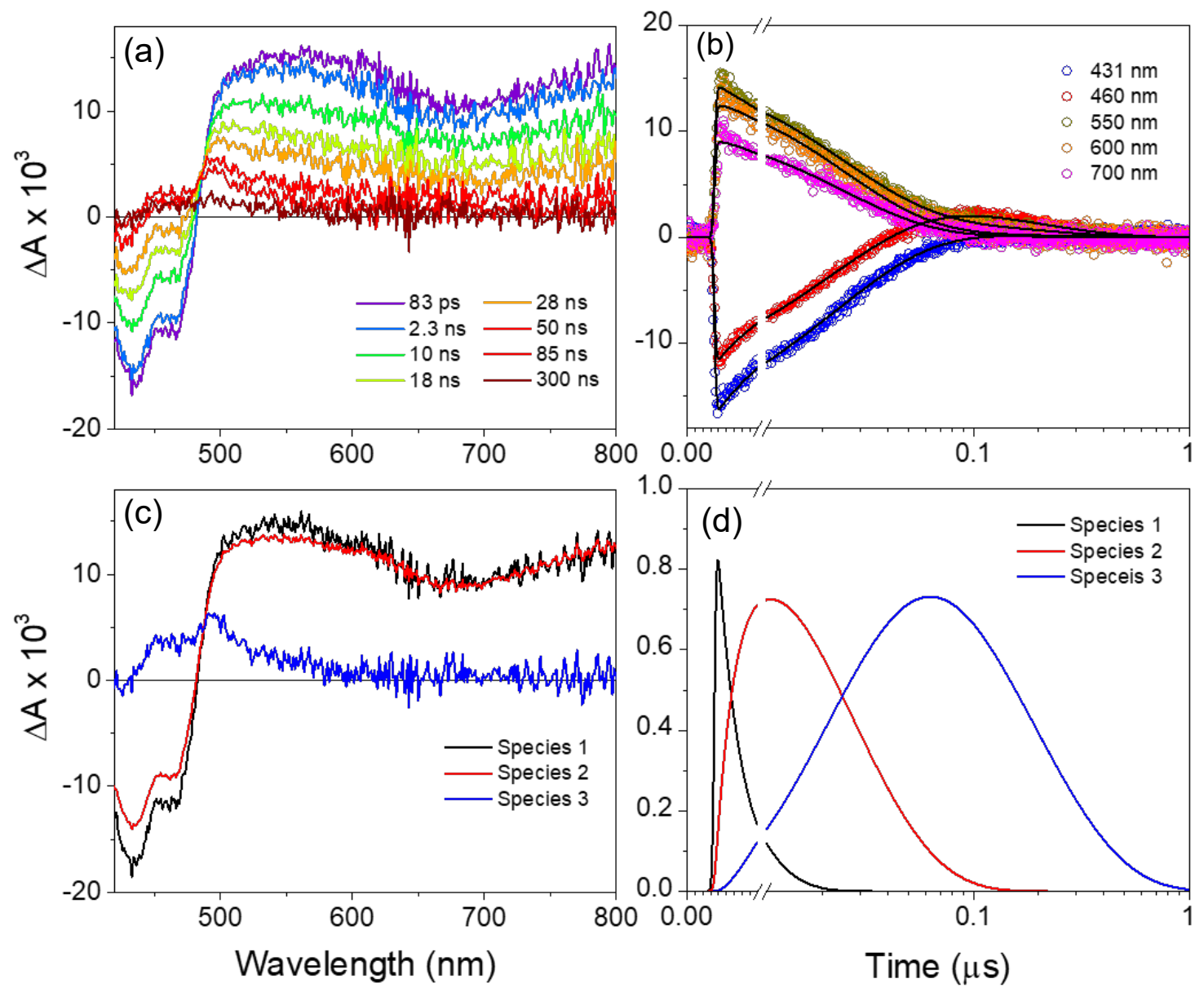

Figure S16. Global analysis of the (a) fsTA data for $\mathbf{0 p h}$ in Tol for the time window of $1 \mu \mathrm{s}$. (b) Wavelength kinetic fits, (c) evolution-associated spectra and (d) population vs. time fits to a sequential $\mathrm{A} \rightarrow \mathrm{B} \rightarrow \mathrm{GS}$ model. Here, species 3 is assigned to the triplet excited state formed by intersystem crossing. 

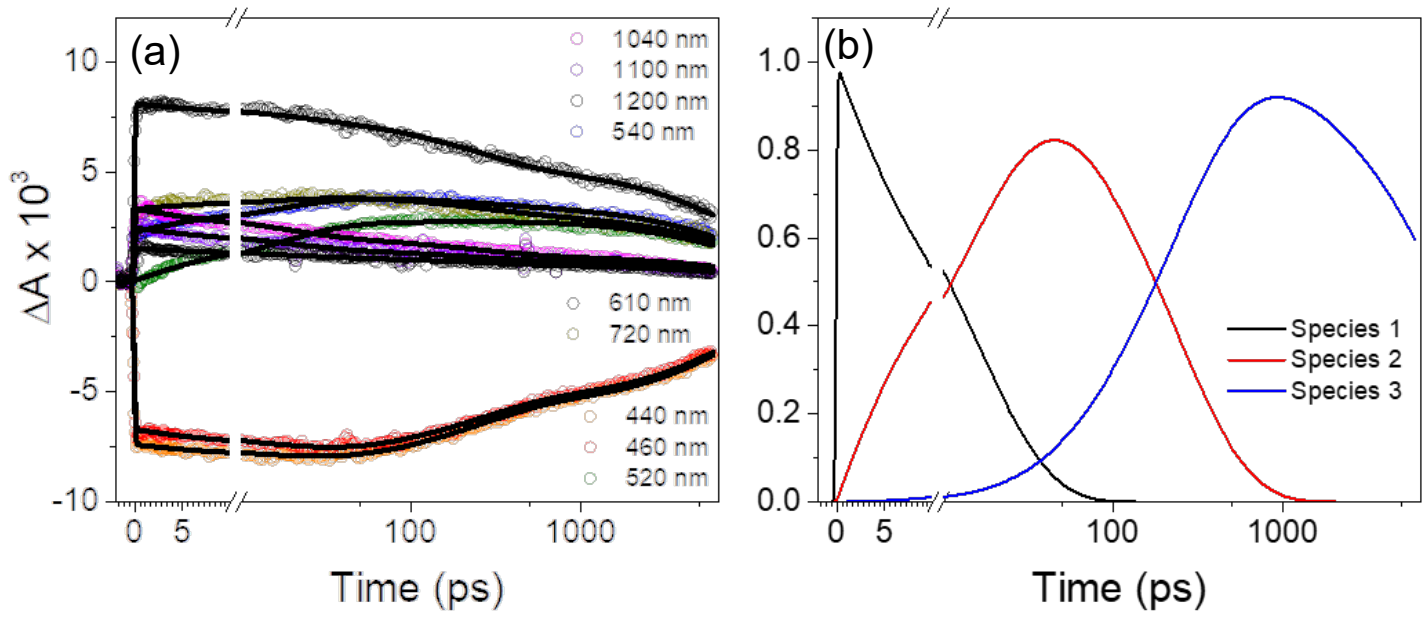

Figure S17. Global analysis of the fsTA data for 1ph in DCM. (a) Kinetic fits to a sequential $\mathrm{A} \rightarrow \mathrm{B} \rightarrow \mathrm{C} \rightarrow \mathrm{GS}$ model and (b) population $v$ s. time fit.
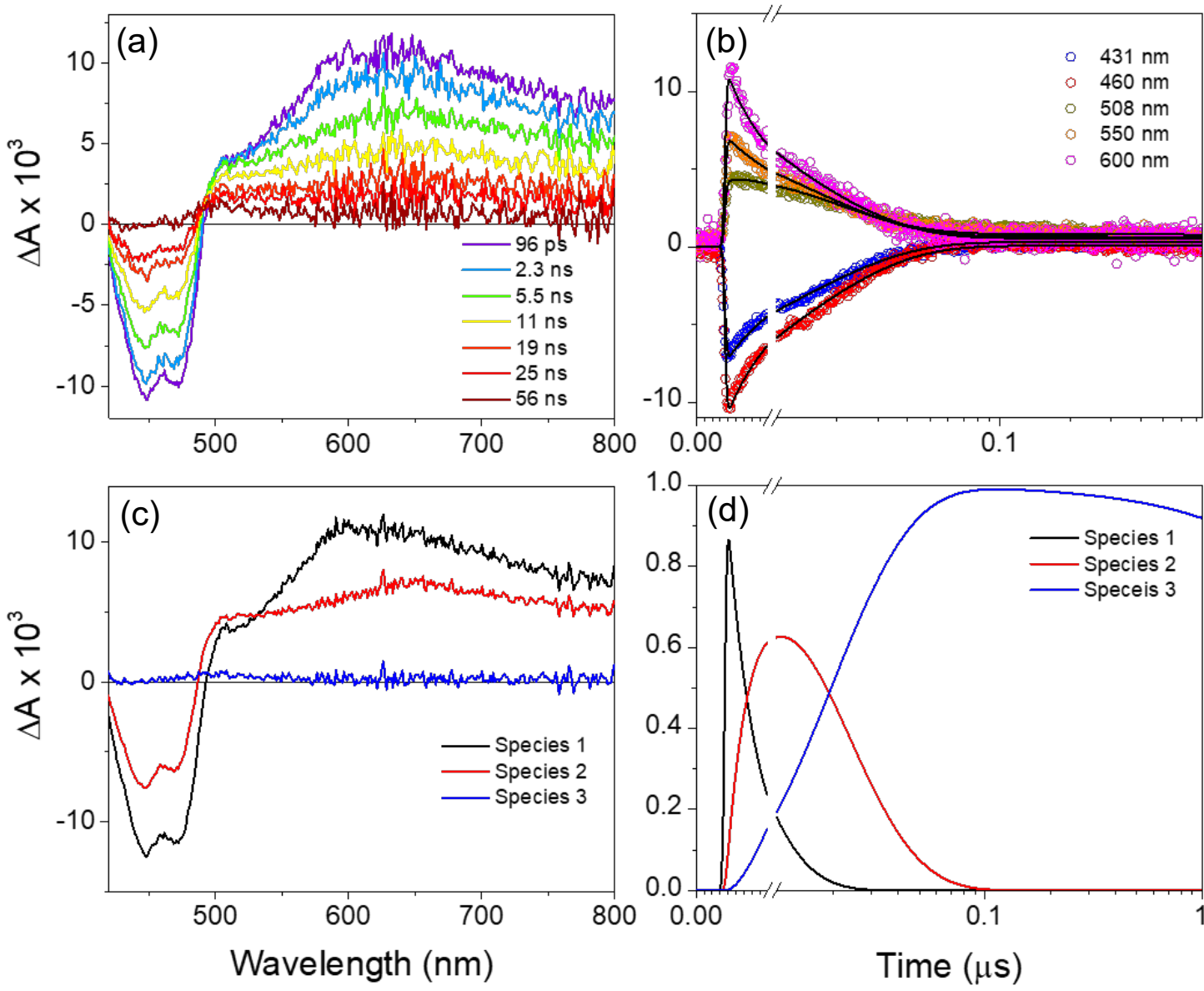

Figure S18. Global analysis of the (a) fsTA data for 1ph in DCM for the time window of $1 \mu$ s. (b) Wavelength kinetic fits, (c) evolution-associated spectra and (d) population vs. time fits to a sequential $\mathrm{A} \rightarrow \mathrm{B} \rightarrow \mathrm{GS}$ model. Here, species 3 is assigned to the triplet excited state formed by intersystem crossing. 

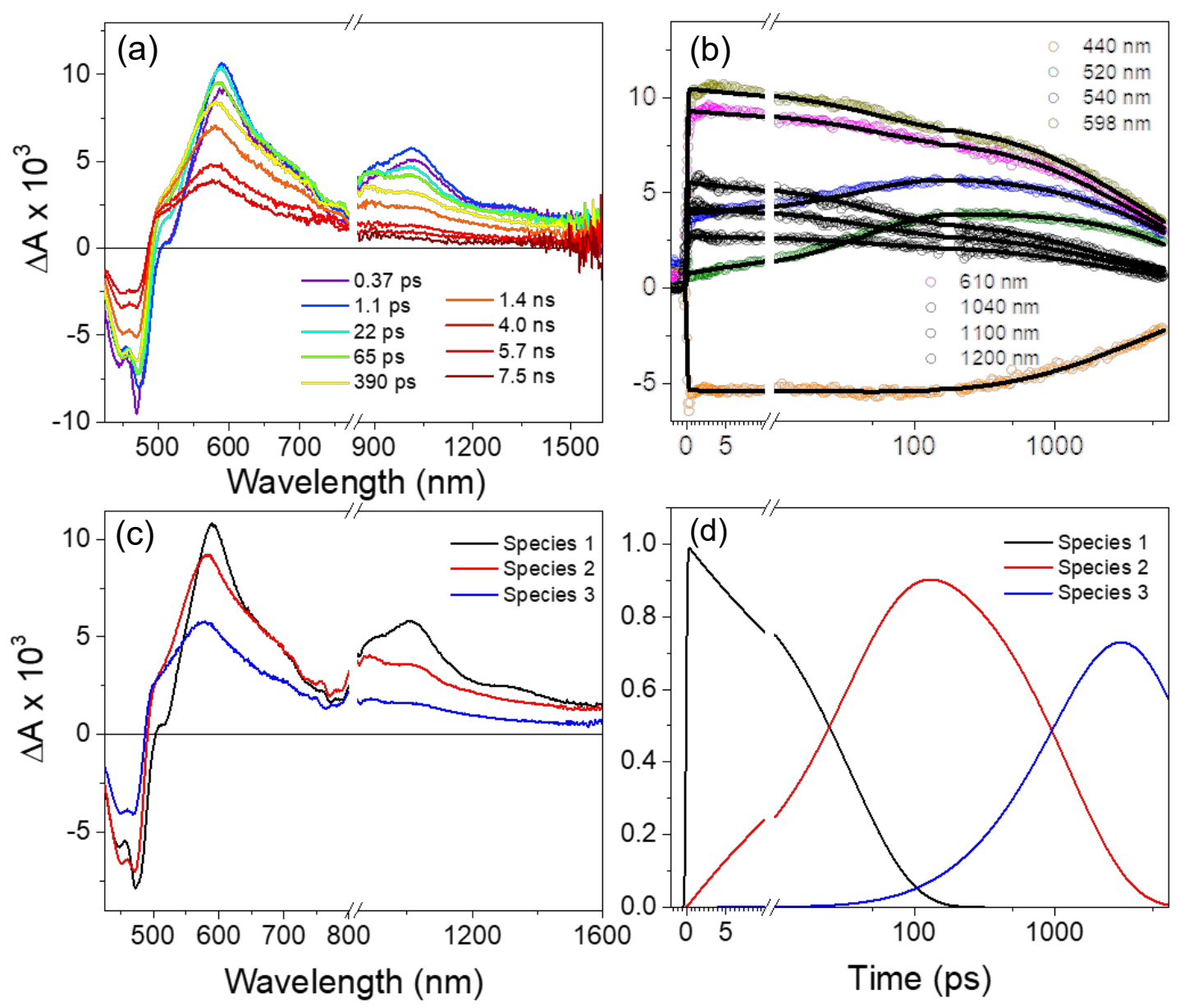

Figure S19. Global analysis of the (a) fsTA data for $\mathbf{1 p h}$ in Tol for the time window of $7.4 \mathrm{~ns}$. (b) Wavelength kinetic fits, (c) evolution-associated spectra and (d) population vs. time fits to a sequential $\mathrm{A} \rightarrow \mathrm{B} \rightarrow \mathrm{C} \rightarrow \mathrm{GS}$ model. 

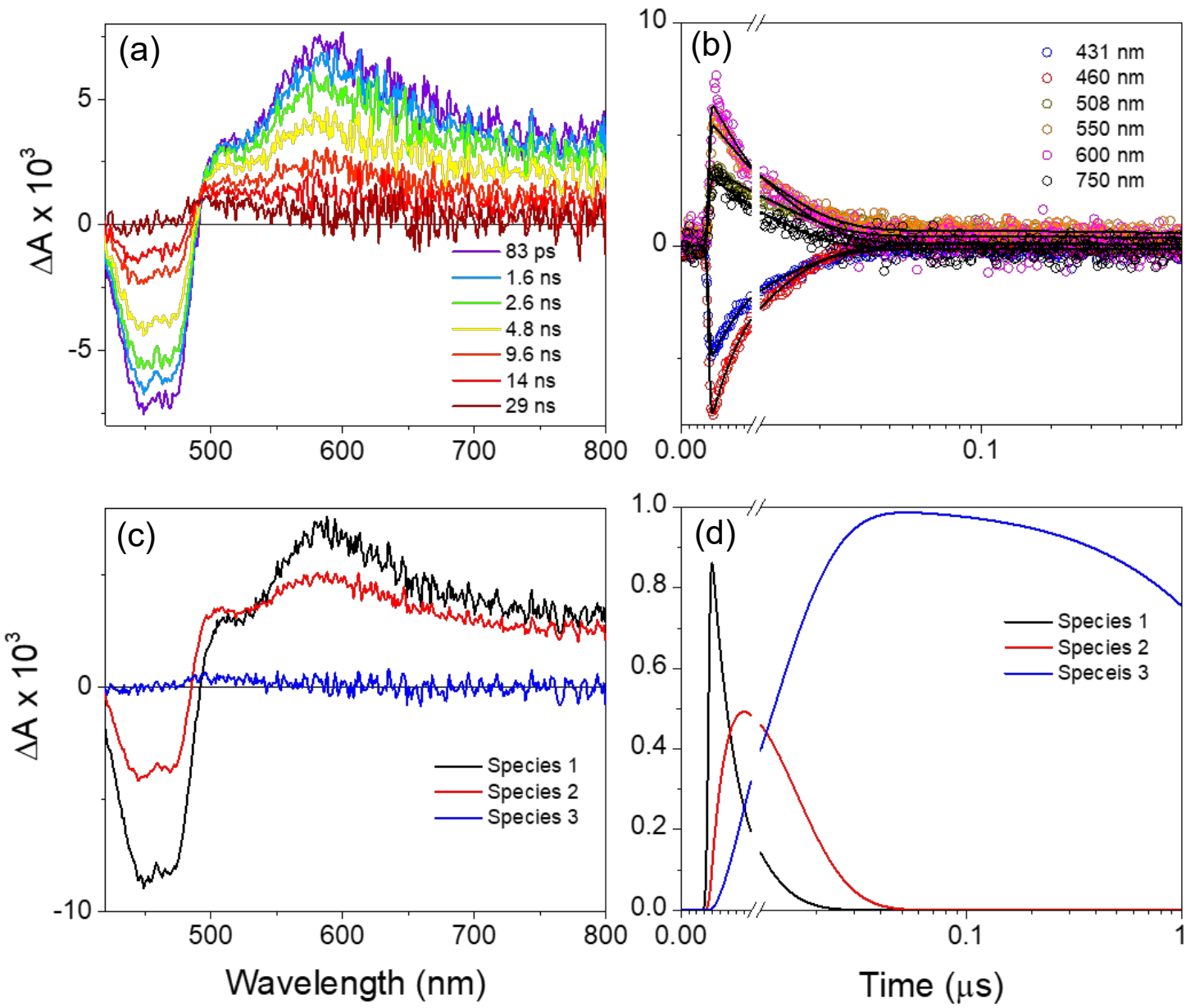

Figure S20. Global analysis of the (a) fsTA data for $1 \mathbf{p h}$ in Tol for the time window of $1 \mu \mathrm{s}$. (b) Wavelength kinetic fits, (c) evolution-associated spectra and (d) population vs. time fits to a sequential $\mathrm{A} \rightarrow \mathrm{B} \rightarrow \mathrm{GS}$ model. Here, species 3 is assigned to the triplet excited state formed by intersystem crossing. 

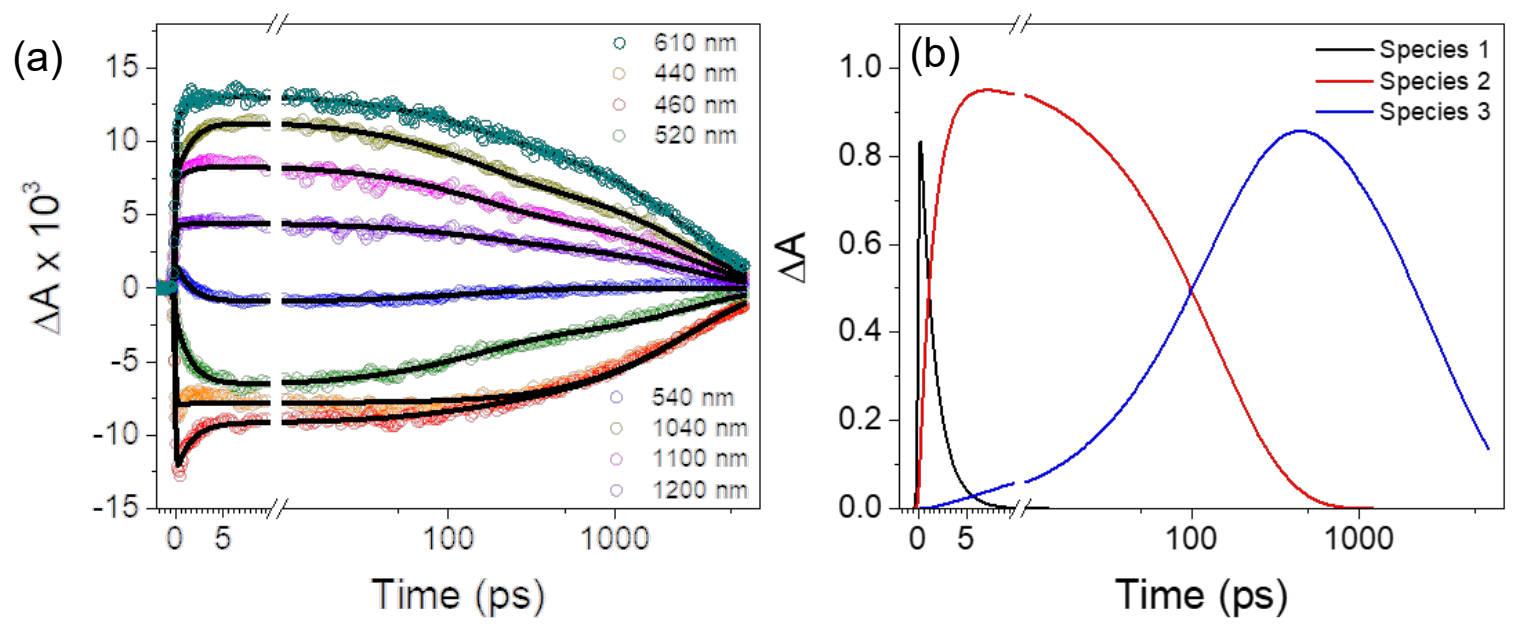

Figure S21. Global analysis of the fsTA data for $\mathbf{2 p h}$ in DCM. (a) Kinetic fits to a sequential $\mathrm{A} \rightarrow \mathrm{B} \rightarrow \mathrm{C} \rightarrow \mathrm{GS}$ model and (b) population vs. time fit.
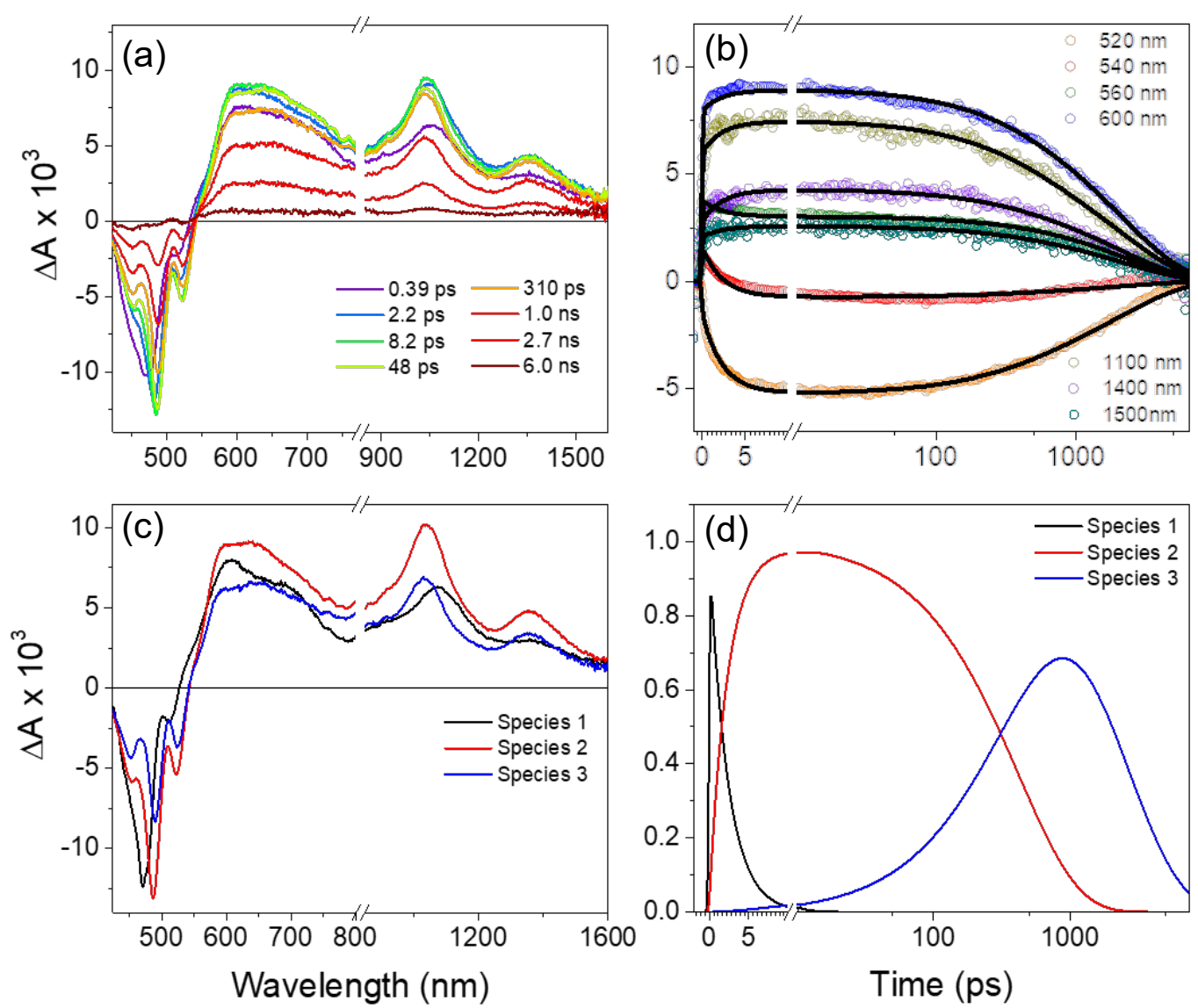

Figure S22. Global analysis of the (a) fsTA data for $\mathbf{2 p h}$ in Tol for the time window of $7.4 \mathrm{~ns}$. (b) Wavelength kinetic fits, (c) evolution-associated spectra and (d) population vs. time fits to a sequential $\mathrm{A} \rightarrow \mathrm{B} \rightarrow \mathrm{C} \rightarrow \mathrm{GS}$ model. 


\section{2ph DMF}

In order to confirm the presence of symmetry-breaking charge separation (SB-CS) occurring in higher polarity solvent, we collected fsTA spectra of $\mathbf{2 p h}$ in DMF. The early time features are similar to those observed in DCM and Tol; however, at later times, there is a distinct new feature around $650 \mathrm{~nm}$, which is assigned to the BPEA anion due to it spectral similarity to the chemically reduced BPEA monomer. ${ }^{2}$ By globally fitting the spectra using $\mathrm{A} \rightarrow \mathrm{B} \rightarrow \mathrm{C} \rightarrow \mathrm{GS}$, three times constants $\left(\tau_{1}=2.3 \pm 0.3 \mathrm{ps}\right),\left(\tau_{2}=110 \pm 3 \mathrm{ps}\right)$, and $\left(\tau_{3}=7.7 \pm 0.2 \mathrm{~ns}\right)$, are obtained. Species 1 is attributed to singlet ESA whereas species 2 and 3 have both singlet ESA shown in the near infrared region and anion feature in the visible region. Thus, $\tau_{1}$ and $\tau_{2}$ are time constants for formation of SB-CS species and $\tau_{3}$ is decay time constant. Note that in both species 2 and 3 there is still a significant amount singlet excited state. These results and the high fluorescence quantum yield indicate that SB-CS is a minor decay pathway in $\mathbf{2} \mathbf{p h}$ and most of the decay is via fluorescence. Presumably, there is a pseudoequilibrium between singlet excited state and CT state, where the amount of CT state increases as the solvent polarity icnreases. ${ }^{3}$ 

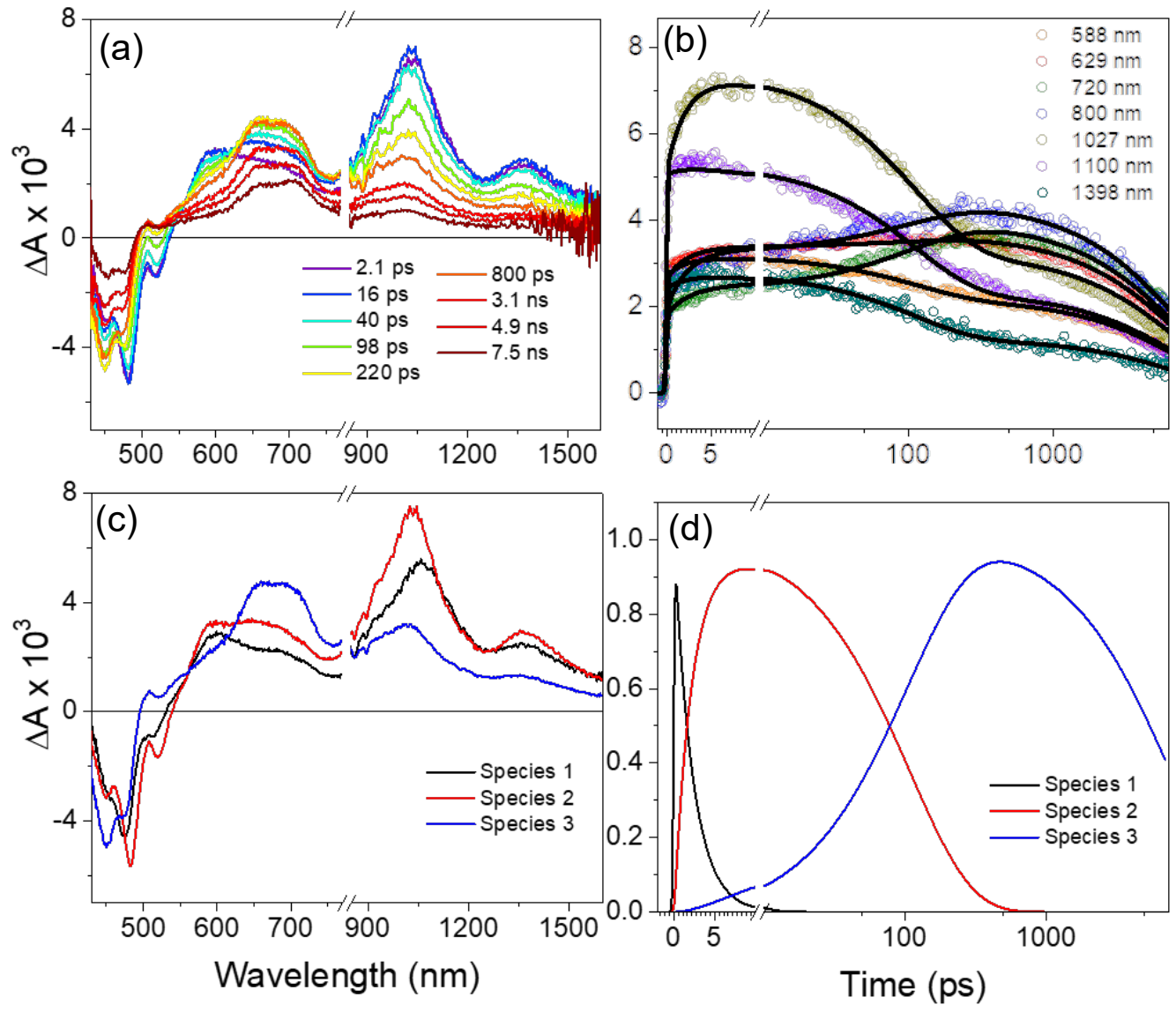

Figure S23. Global analysis of the (a) fsTA data for $\mathbf{2 p h}$ in DMF for the time window of 7.4 ns. (b) Wavelength kinetic fits, (c) evolution-associated spectra and (d) population vs. time fits to a sequential $\mathrm{A} \rightarrow \mathrm{B} \rightarrow \mathrm{C} \rightarrow$ GS kinetic model. 


\section{Computational Details}

\section{a. Transfer integrals calculation}
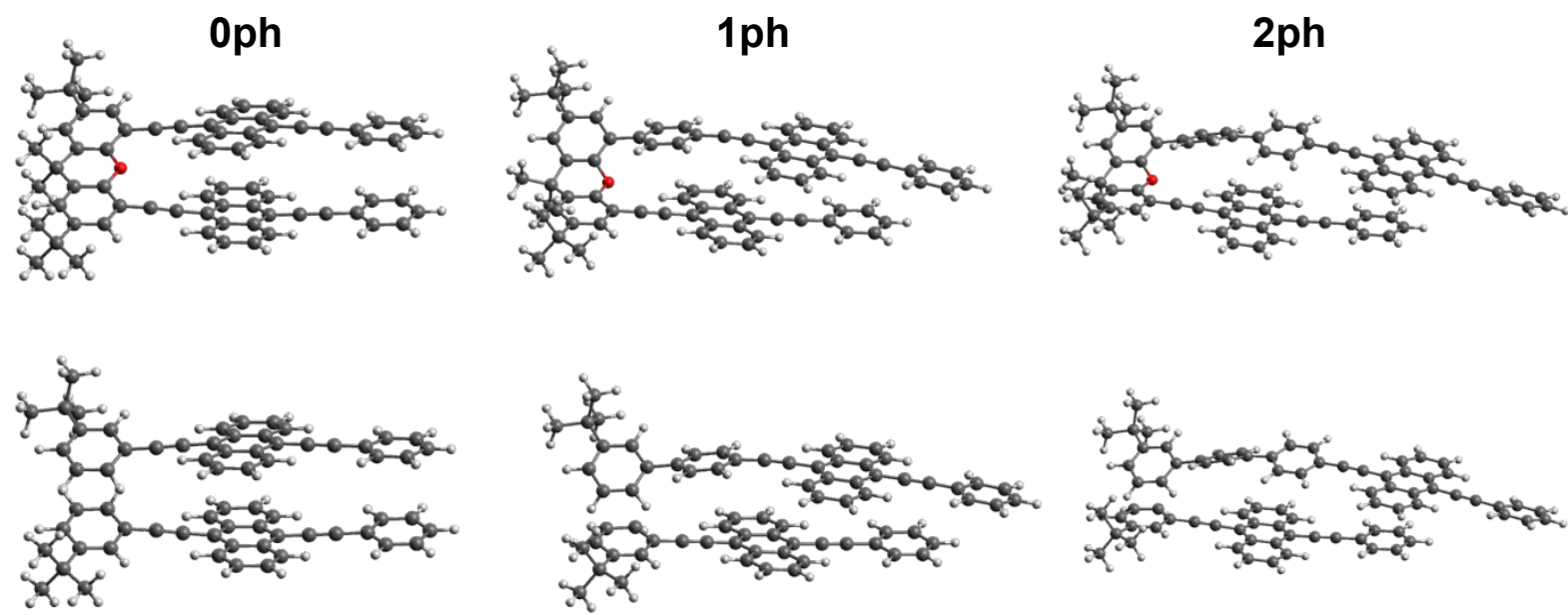

Figure S24. (Top) Geometry optimized BPEA dimers using B3LYP basis and Grimme3 dispersion correction functional. (Bottom) Fragmented BPEA dimers.

Table S2. The calculated matrix elements $S, J$, and $V$. All units are in meV.

\begin{tabular}{|c|c|c|c|c|c|c|}
\hline$(\mathrm{meV})$ & $\boldsymbol{S}_{\mathbf{H H}}$ & $\boldsymbol{S}_{\mathbf{L L}}$ & $\boldsymbol{J}_{\mathbf{H H}}$ & $\boldsymbol{J}_{\mathbf{L L}}$ & $\boldsymbol{V}_{\mathbf{H H}}$ & $\boldsymbol{V}_{\mathbf{L L}}$ \\
\hline $\mathbf{0 p h}$ & 2.65 & -9.85 & -45.5 & 85.6 & -31.5 & 59.6 \\
\hline $\mathbf{1 p h}$ & 5.36 & -2.94 & -59.7 & 25.3 & -31.4 & 17.5 \\
\hline $\mathbf{2 p h}$ & -8.35 & -2.05 & 95.2 & 13.9 & 51 & 8.31 \\
\hline
\end{tabular}

\section{b. S1 energy calculation using TDDFT}

We calculated the $\mathrm{S}_{1}$ energies of the BPEA and PDI monomers (Figure S25) using QChem (version 5.0). ${ }^{4}$ The optimized ground state geometries were calculated using DFT and the excited state energies were calculated using TDDFT at the B3LYP/6-31G* level by specifying the dielectric constants of DCM and Tol. The calculated $\mathrm{S}_{1}$ energy for BPEA is $2.34 \mathrm{eV}$ in DCM and Tol. For the PDI monomer, the $\mathrm{S}_{1}$ energy is $2.23 \mathrm{eV}$ in DCM and $2.24 \mathrm{eV}$ in Tol. 
c. Charge transfer state energy calculation<smiles>C(#Cc1c2ccccc2c(C#Cc2ccccc2)c2ccccc12)c1ccccc1</smiles>

BPEA<smiles></smiles>

PDI-ref

Figure S25. BPEA monomer and PDI-ref molecule used to calculate singlet point energy of the neutral, cation and anion using PCM model.

Table S3. Single point energy of BPEA and PDI-ref in DCM and Tol. Energy units are in Hartrees.

\begin{tabular}{|c|c|c|c|}
\hline & $\begin{array}{c}\text { BPEA } \\
\text { DCM }\end{array}$ & BPEA Tol & PDI-ref DCM \\
\hline Neutral & -1152.61 & -1152.60 & -1714.12 \\
\hline Cation & -1152.42 & -1152.40 & -1713.90 \\
\hline Anion & -1152.70 & -1152.68 & -1714.24 \\
\hline CT state & 0.09105 & 0.1215 & 0.08239 \\
\hline CT state (eV) & 2.48 & 3.30 & 2.24 \\
\hline
\end{tabular}

Example calculation of $E(\mathrm{CT})$ of BPEA in DCM

$E($ Cation $*)=E($ cation $)-E($ Neutral $)$

$E($ Anion* $)=E($ Anion $)-E($ Neutral $)$

$E(\mathrm{CT})=E($ Cation $*)+E($ Anion* $)$

\section{d. Exciton coupling $J$ calculation}

We simulated the steady-state absorption spectra of the BPEA compounds using a Frenkel/chargetransfer (CT) Holstein Hamiltonian. ${ }^{5-6}$ Briefly, the time-independent system Hamiltonian is written 
as a combination of Frenkel exciton and CT contributions as well as the coupling elements between these two species:

$$
H_{s y s}=H_{F E}+H_{C T}+H_{F E-C T}
$$

The Frenkel exciton portion is formulated as follows:

$$
\begin{aligned}
H_{F E}= & \varepsilon_{n} \sum_{n} c_{n}^{\dagger} c_{n}+J \sum_{n \neq n^{\prime}} c_{n}^{\dagger} c_{n^{\prime}}+\omega_{0} \sum_{n} b_{n}^{\dagger} b_{n} \\
& +\omega_{0} \sum_{n} c_{n}^{\dagger} c_{n}\left[\lambda\left(b_{n}^{\dagger}+b_{n}\right)+\lambda^{2}\right]
\end{aligned}
$$

where $\varepsilon_{n}$ represents the singlet electronic transition energy of chromophore $n$ in the dimer $(n=1$, 2), $c_{n}^{(\dagger)}$ and $b_{n}{ }^{(\dagger)}$ annihilate (create) singlet electronic and vibrational quanta, respectively, on chromophore $n, J$ tailors the strength of the coulombic coupling between the chromophores, $\omega_{0}$ is the frequency of the vibration, and $\lambda^{2}$ is the Huang-Rhys factor. We dress both Frenkel-exciton and CT-type states with a single, identical vibration since the broad linewidths in our linear absorption spectra yield reliable information for only one Franck-Condon-active mode. We restricted the number of vibrational quanta within the system to a maximum of 10 to ease computational effort while still capturing transitions to higher lying vibronic states.

The CT Hamiltonian is expressed as follows:

$$
\begin{aligned}
H_{C T}= & \varepsilon_{C T} \sum_{n \neq n^{\prime}} d_{n}^{\dagger} d_{n} f_{n^{\prime}}^{\dagger} f_{n^{\prime}} \\
& +\omega_{0} \sum_{n \neq n^{\prime}}\left[\lambda_{+}\left(b_{n}^{\dagger}+b_{n}\right)+\lambda_{-}\left(b_{n^{\prime}}^{\dagger}+b_{n^{\prime}}\right)+\lambda_{+}^{2}+\lambda_{-}^{2}\right] d_{n}^{\dagger} d_{n} f_{n^{\prime}}^{\dagger} f_{n^{\prime}}
\end{aligned}
$$

where $\varepsilon_{\mathrm{CT}}$ represents the electronic energy of the $\mathrm{CT}$ state relative to the ground electronic configuration, $\lambda_{+}{ }^{2}$ and $\lambda_{-}^{2}$ are the Huang-Rhys factors of the cation and anion, respectively, and 
the operators $\mathrm{d}_{\mathrm{n}}^{(\dagger)}$ and $\mathrm{f}_{\mathrm{n}}^{(\dagger)}$ annihilate (create) a hole or electron in the HOMO or LUMO of chromophore $n$, respectively. We assume $\lambda^{2}=\lambda_{+}{ }^{2}$ and $\lambda_{-}^{2}$. The coupling between Frenkel exciton and CT states is written as:

$$
H_{F E-C T}=\sum_{n \neq n \prime} t_{h}\left(c_{n}^{\dagger} d_{n^{\prime}}+d_{n^{\prime}}^{\dagger} c_{n}\right)+t_{e}\left(c_{n}^{\dagger} f_{n^{\prime}}+f_{n^{\prime}}^{\dagger} c_{n}\right)
$$

where $t_{h}$ and $t_{e}$ are the computed electron and hole transfer integrals.

In simulating the light-matter interaction, we restrict the transition dipole operator to excitation of singlet electronic states, thereby neglecting the weak direct excitation of the CT state:

$$
\mu\left(\tau_{i}\right)=\sum_{n=1,2} \mu_{n}^{E}\left(c_{n}^{\dagger}+c_{n}\right)
$$

where $\tau_{i}$ reflects the time of optical interaction $i$, and $\mu_{n}{ }^{E}$ reflects the magnitude of the interaction with the electric field with chromophore $n$. We do not extract the latter parameter due to normalization of the computed and experimental spectra. Assuming the system begins in the ground vibrational state $\left(\omega_{0}>>k_{b} T\right)$, the time-domain linear response involving two impulsive optical field interactions at times $\tau_{1}$ and $\tau_{2}$ is expressed as:

$$
R(\tau)=\left\langle 0\left|\mu\left(\tau_{2}\right) U\left(\tau_{2}, \tau_{1}\right) \mu\left(\tau_{1}\right)\right| 0\right\rangle
$$

Free propagation under the system Hamiltonian during the inter-pulse time delay $(t)$ is captured by the operator $U$ :

$$
U(\tau)=\exp \left(-i H_{\text {sys }} t\right)
$$

To ease computational time by minimizing the number of timepoints while avoiding aliasing effects, we subtract the singlet transition energy from all diagonal elements of the system Hamiltonian, except for the ground-state diagonal elements. This is corrected at the end of the 
simulation by shifting the Fourier frequency axis by the subtracted transition energy. We propagate the system over an inter-pulse time delay range of 0 to $256 \mathrm{fs}$ with a $1 \mathrm{fs}$ step size. Spectral linewidths were imposed by multiplying the time-domain linear response by a Gaussian windowing function. The width of this windowing function was held constant for all the dimeric systems. The absorption spectrum was obtained via fast Fourier transformation of equation S6 after windowing and zero-padding to a vector length of $2^{10}$
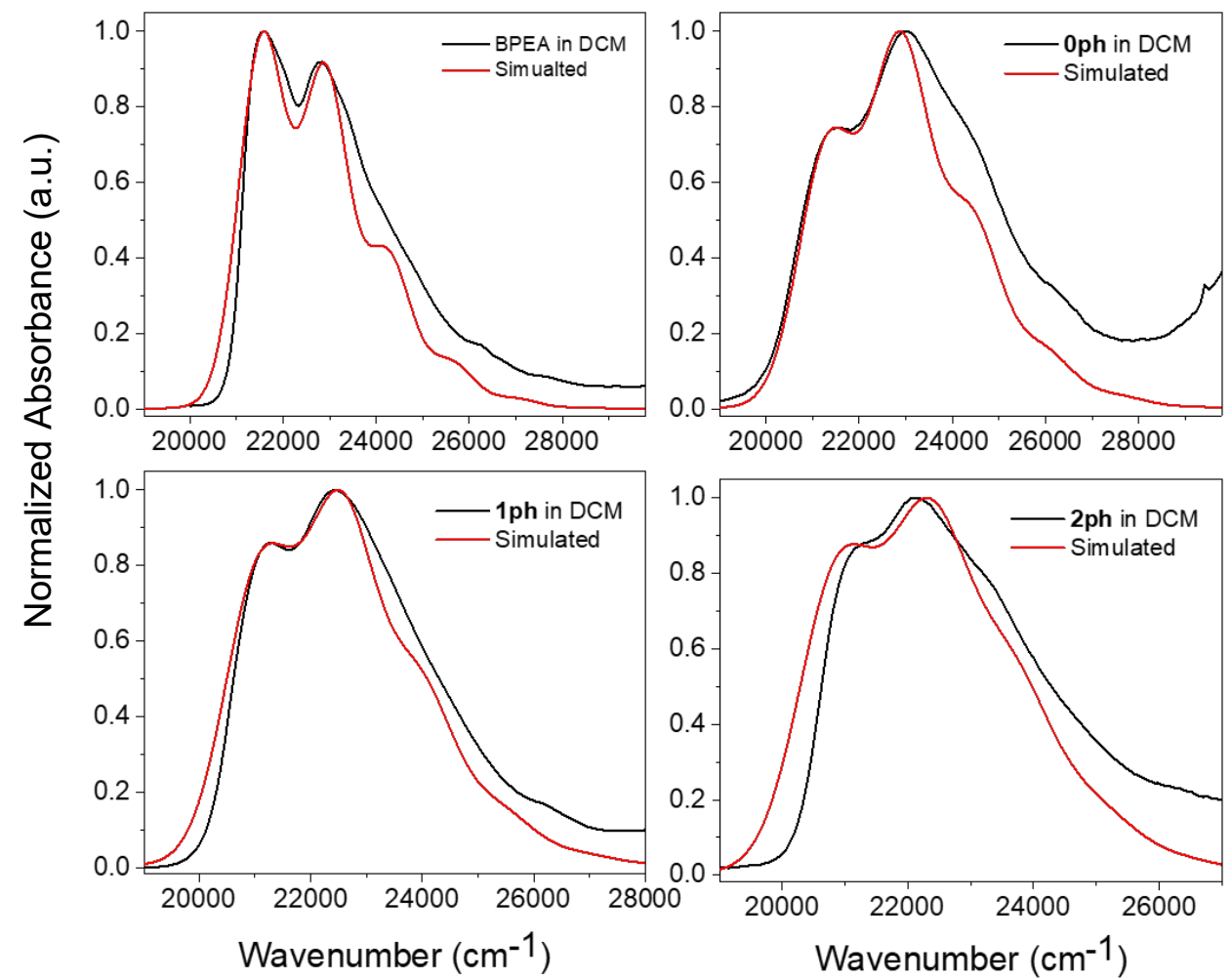

Figure S26. Simulated absorbance spectra of BPEA monomer and dimers in DCM to calculate $J$. 
e. Coulomb coupling in BPEA and DPP crystals

The Coulomb coupling $J_{\text {coulb }}$ is calculated by using the following equation under the pointdipole approximation: ${ }^{7-8}$

$$
J_{\text {Coulb }}=\frac{\mu^{2}\left(1-3 \cos ^{2} \theta\right)}{4 \pi \varepsilon R^{3}}
$$

Here, the parameters defining the relative orientation between the two molecules, $\mathrm{R}$ and $\theta$ are obtained from the reported crystal structures of $\mathrm{DPP}^{9}$ and $\mathrm{BPEA}^{10}$ and the values are shown in Table S5. The same dimer is used to calculate the HOMO-HOMO and LUMO-LUMO coupling. The previously reported transition dipole moments, $\mu$ of BPEA $(4.05 \mathrm{D})^{11}$ and DPP $(5.6 \mathrm{D})^{12}$ are used to calculate $J_{\text {coulb, }}$

Table S4. The relative orientation between the two molecules, R and $\theta$ in BPEA and DPP crystals

\begin{tabular}{ccccccc}
\hline & BPEA C2/c & BPEA Pbcn & C6 DPP & Me DPP & TEG DPP & Ph DPP \\
\hline $\mathrm{R}(\mathrm{nm})$ & 0.5357 & 0.4866 & 0.5391 & 0.4906 & 0.7285 & 0.6257 \\
$\theta\left(^{\circ}\right)$ & 85.7 & 81.6 & 41.4 & 48.9 & 30.1 & 34.0 \\
$J_{\text {coulb }}\left(\mathrm{cm}^{-1}\right)$ & 401 & 510 & -692 & -400 & -510 & -685 \\
\hline
\end{tabular}




\section{f. Excimer eigenstates calculation}

The coefficients $\mathrm{a}$ and $\mathrm{b}$ are calculated by diagonalizing the $4 \times 4$ matrix, as shown in the top 5 rows in the below table, using the eig function in MATLAB. The 4 eigenstates are shown in the bottom rows followed by the corresponding eigenvalues, which are excimer state energies shown in the last row.

For BPEA covalent dimers, each component is calculated in this work and is thoroughly described above. For PDI covalent dimers only the $\mathrm{S}_{1}$ and CT energies are calculated in this work and other components are from the previous work. ${ }^{13}$ For BPEA and DPP solid-state systems, only

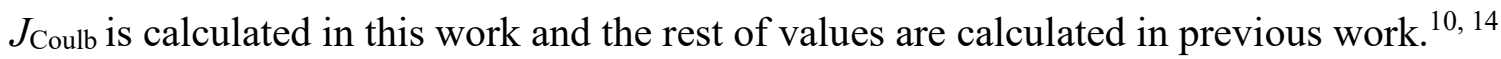

Table S5. Key to data table for excimer eigenstate calculations.

\begin{tabular}{|c|c|c|c|c|}
\hline Sample $\left(\mathrm{cm}^{-1}\right)$ & S0S1 & S1S0 & $\mathrm{CA}$ & $\mathrm{AC}$ \\
\hline S0S1 & $E\left(\mathrm{~S}_{1}\right)$ & $J_{\text {Coulb }}$ & $V_{\mathrm{HH}}$ & $V_{\mathrm{LL}}$ \\
\hline S1S0 & $J_{\text {Coulb }}$ & $E\left(\mathrm{~S}_{1}\right)$ & $V_{\mathrm{LL}}$ & $V_{\mathrm{HH}}$ \\
\hline CA & $V_{\mathrm{HH}}$ & $V_{\mathrm{LL}}$ & $E(\mathrm{CT})$ & 0 \\
\hline $\mathrm{AC}$ & $V_{\mathrm{LL}}$ & $V_{\mathrm{HH}}$ & 0 & $E(\mathrm{CT})$ \\
\hline \multicolumn{5}{|c|}{ eigenstates } \\
\hline & Excimer 1 & Excimer 2 & Excimer 3 & Excimer 4 \\
\hline Sample & S0S1 & S1S0 & $\mathrm{CA}$ & $\mathrm{AC}$ \\
\hline S0S1 & $\mathrm{a}(\mathrm{Ex} 1)$ & $\mathrm{a}(\mathrm{Ex} 2)$ & $\mathrm{a}(\mathrm{Ex} 3)$ & $\mathrm{a}(\mathrm{Ex} 4)$ \\
\hline S1S0 & $\mathrm{a}(\mathrm{Ex} 1)$ & $\mathrm{a}(\mathrm{Ex} 2)$ & $\mathrm{a}(\mathrm{Ex} 3)$ & $\mathrm{a}(\mathrm{Ex} 4)$ \\
\hline $\mathrm{CA}$ & $\mathrm{b}(\mathrm{Ex} 1)$ & $b(E x 2)$ & $\mathrm{b}(\mathrm{Ex} 3)$ & $\mathrm{b}(\mathrm{Ex} 4)$ \\
\hline $\mathrm{AC}$ & $\mathrm{b}(\mathrm{Ex} 1)$ & $\mathrm{b}(\mathrm{Ex} 2)$ & $\mathrm{b}(\mathrm{Ex} 3)$ & $\mathrm{b}(\mathrm{Ex} 4)$ \\
\hline \multicolumn{5}{|c|}{ eigenvalues } \\
\hline Sample (eV) & $E(\mathrm{Ex} 1)$ & $E(\mathrm{Ex} 2)$ & $E(\mathrm{Ex} 3)$ & $E(\mathrm{Ex} 4)$ \\
\hline
\end{tabular}


Table S6. 0ph DCM

\begin{tabular}{|c|c|c|c|c|}
\hline Oph $\left(\mathrm{cm}^{-1}\right)$ & S0S1 & S1S0 & CA & $\mathrm{AC}$ \\
\hline S0S1 & 18911 & 270 & -254 & 481 \\
\hline S1S0 & 270 & 18911 & 481 & -254 \\
\hline CA & -254 & 481 & 19977 & 0 \\
\hline $\mathrm{AC}$ & 481 & -254 & 0 & 19977 \\
\hline \multicolumn{5}{|c|}{ eigenstates } \\
\hline & Excimer 1 & Excimer 2 & Excimer 3 & Excimer 4 \\
\hline Oph & S0S1 & S1S0 & CA & $\mathrm{AC}$ \\
\hline S0S1 & 0.6466 & 0.6835 & 0.1812 & -0.2861 \\
\hline S1S0 & -0.6466 & 0.6835 & 0.1812 & 0.2861 \\
\hline $\mathrm{CA}$ & 0.2861 & -0.1812 & 0.6835 & 0.6466 \\
\hline $\mathrm{AC}$ & -0.2861 & -0.1812 & 0.6835 & -0.6466 \\
\hline \multicolumn{5}{|c|}{ eigenvalues } \\
\hline Oph $(\mathrm{eV})$ & 2.2710 & 2.3708 & 2.4845 & 2.5173 \\
\hline
\end{tabular}

Table S7. Oph Tol

\begin{tabular}{|c|c|c|c|c|}
\hline Oph $\left(\mathrm{cm}^{-1}\right)$ & S0S1 & S1S0 & CA & $\mathrm{AC}$ \\
\hline S0S1 & 18909 & 370 & -254 & 481 \\
\hline S1S0 & 370 & 18909 & 481 & -254 \\
\hline CA & -254 & 481 & 26676 & 0 \\
\hline $\mathrm{AC}$ & 481 & -254 & 0 & 26676 \\
\hline \multicolumn{5}{|c|}{ eigenstates } \\
\hline & Excimer 1 & Excimer 2 & Excimer 3 & Excimer 4 \\
\hline Oph & S0S1 & S1S0 & CA & $\mathrm{AC}$ \\
\hline S0S1 & 0.7043 & 0.7068 & 0.0217 & 0.0631 \\
\hline S1S0 & -0.7043 & 0.7068 & 0.0217 & -0.0631 \\
\hline CA & 0.0631 & -0.0217 & 0.7068 & -0.7043 \\
\hline $\mathrm{AC}$ & -0.0631 & -0.0217 & 0.7068 & 0.7043 \\
\hline \multicolumn{5}{|c|}{ eigenvalues } \\
\hline Oph $(\mathrm{eV})$ & 2.2905 & 2.3896 & 3.3085 & 3.3158 \\
\hline
\end{tabular}


Table S8. 1ph DCM

\begin{tabular}{|c|c|c|c|c|}
\hline $1 \mathrm{ph}\left(\mathrm{cm}^{-1}\right)$ & S0S1 & S1S0 & CA & $\mathrm{AC}$ \\
\hline S0S1 & 18911 & 210 & -253 & 141 \\
\hline S1S0 & 210 & 18911 & 141 & -253 \\
\hline CA & -253 & 141 & 19977 & 0 \\
\hline $\mathrm{AC}$ & 141 & -253 & 0 & 19977 \\
\hline \multicolumn{5}{|c|}{ eigenstates } \\
\hline & Excimer 1 & Excimer 2 & Excimer 3 & Excimer 4 \\
\hline $1 \mathrm{ph}$ & S0S1 & S1S0 & CA & $\mathrm{AC}$ \\
\hline S0S1 & 0.6802 & 0.7013 & -0.0902 & 0.1931 \\
\hline S1S0 & -0.6802 & 0.7013 & -0.0902 & -0.1931 \\
\hline $\mathrm{CA}$ & 0.1931 & 0.0902 & 0.7013 & -0.6802 \\
\hline $\mathrm{AC}$ & -0.1931 & 0.0902 & 0.7013 & 0.6802 \\
\hline \multicolumn{5}{|c|}{ eigenvalues } \\
\hline 1ph $(\mathrm{eV})$ & 2.3049 & 2.3691 & 2.4788 & 2.4909 \\
\hline
\end{tabular}

Table S9. 1ph Tol

\begin{tabular}{|c|c|c|c|c|}
\hline $1 \mathrm{ph}\left(\mathrm{cm}^{-1}\right)$ & S0S1 & S1S0 & CA & $\mathrm{AC}$ \\
\hline S0S1 & 18909 & 245 & -253 & 141 \\
\hline S1S0 & 245 & 18909 & 141 & -253 \\
\hline $\mathrm{CA}$ & -253 & 141 & 26676 & 0 \\
\hline $\mathrm{AC}$ & 141 & -253 & 0 & 26676 \\
\hline \multicolumn{5}{|c|}{ eigenstates } \\
\hline & Excimer 1 & Excimer 2 & Excimer 3 & Excimer 4 \\
\hline $1 \mathrm{ph}$ & S0S1 & S1S0 & CA & AC \\
\hline S0S1 & 0.7063 & 0.707 & -0.0105 & 0.0346 \\
\hline S1S0 & -0.7063 & 0.707 & -0.0105 & -0.0346 \\
\hline CA & 0.0346 & 0.0105 & 0.707 & -0.7063 \\
\hline $\mathrm{AC}$ & -0.0346 & 0.0105 & 0.707 & 0.7063 \\
\hline \multicolumn{5}{|c|}{ eigenvalues } \\
\hline 1ph $(\mathrm{eV})$ & 2.3118 & 2.3747 & 3.3078 & 3.3100 \\
\hline
\end{tabular}


Table S10. 2ph DCM

\begin{tabular}{|c|c|c|c|c|}
\hline $2 \mathrm{ph}\left(\mathrm{cm}^{-1}\right)$ & S0S1 & S1S0 & CA & $\mathrm{AC}$ \\
\hline S0S1 & 18911 & 220 & 411 & 67 \\
\hline S1S0 & 220 & 18911 & 67 & 411 \\
\hline $\mathrm{CA}$ & 411 & 67 & 19977 & 0 \\
\hline $\mathrm{AC}$ & 67 & 411 & 0 & 19977 \\
\hline \multicolumn{5}{|c|}{ eigenstates } \\
\hline & Excimer 1 & Excimer 2 & Excimer 3 & Excimer 4 \\
\hline $2 \mathrm{ph}$ & S0S1 & S1S0 & CA & $\mathrm{AC}$ \\
\hline S0S1 & -0.6859 & -0.6447 & -0.1719 & 0.2904 \\
\hline S1S0 & 0.6859 & -0.6447 & 0.1719 & 0.2904 \\
\hline $\mathrm{CA}$ & 0.1719 & 0.2904 & -0.6859 & 0.6447 \\
\hline $\mathrm{AC}$ & -0.1719 & 0.2904 & 0.6859 & 0.6447 \\
\hline \multicolumn{5}{|c|}{ eigenvalues } \\
\hline 2ph $(\mathrm{eV})$ & 2.3069 & 2.3454 & 2.4877 & 2.5037 \\
\hline
\end{tabular}

Table S11. 2ph Tol

\begin{tabular}{|c|c|c|c|c|}
\hline $2 \mathrm{ph}\left(\mathrm{cm}^{-1}\right)$ & S0S1 & S1S0 & CA & $\mathrm{AC}$ \\
\hline S0S1 & 18909 & 240 & 411 & 67 \\
\hline S1S0 & 240 & 18909 & 67 & 411 \\
\hline $\mathrm{CA}$ & 411 & 67 & 26676 & 0 \\
\hline $\mathrm{AC}$ & 67 & 411 & 0 & 26676 \\
\hline \multicolumn{5}{|c|}{ eigenstates } \\
\hline & Excimer 1 & Excimer 2 & Excimer 3 & Excimer 4 \\
\hline $2 \mathrm{ph}$ & S0S1 & S1S0 & CA & $\mathrm{AC}$ \\
\hline S0S1 & -0.7065 & 0.7057 & 0.0303 & 0.0446 \\
\hline S1S0 & 0.7065 & 0.7057 & -0.0303 & 0.0446 \\
\hline $\mathrm{CA}$ & 0.0303 & -0.0446 & 0.7065 & 0.7057 \\
\hline $\mathrm{AC}$ & -0.0303 & -0.0446 & -0.7065 & 0.7057 \\
\hline \multicolumn{5}{|c|}{ eigenvalues } \\
\hline 2ph $(\mathrm{eV})$ & 2.3130 & 2.3706 & 3.3095 & 3.3114 \\
\hline
\end{tabular}


Table S12. C2/c BPEA solid-state sample

\begin{tabular}{|c|c|c|c|c|}
\hline $\mathrm{C} 2 / \mathrm{c}\left(\mathrm{cm}^{-1}\right)$ & S0S1 & S1S0 & $\mathrm{CA}$ & $\mathrm{AC}$ \\
\hline S0S1 & 20485 & 401 & -404 & 968 \\
\hline S1S0 & 401 & 20485 & 968 & -404 \\
\hline $\mathrm{CA}$ & -404 & 968 & 28308 & 0 \\
\hline $\mathrm{AC}$ & 968 & -404 & 0 & 28308 \\
\hline \multicolumn{5}{|c|}{ eigenstates } \\
\hline & Excimer 1 & Excimer 2 & Excimer 3 & Excimer 4 \\
\hline $\mathrm{C} 2 / \mathrm{c}$ & S0S1 & S1S0 & $\mathrm{CA}$ & $\mathrm{AC}$ \\
\hline S0S1 & 0.698 & 0.7051 & 0.0533 & 0.1134 \\
\hline S1S0 & -0.698 & 0.7051 & 0.0533 & -0.1134 \\
\hline $\mathrm{CA}$ & 0.1134 & -0.0533 & 0.7051 & -0.698 \\
\hline $\mathrm{AC}$ & -0.1134 & -0.0533 & 0.7051 & 0.698 \\
\hline \multicolumn{5}{|c|}{ eigenvalues } \\
\hline $\mathbf{C 2} / \mathbf{c}(\mathrm{eV})$ & 1.9861 & 2.0843 & 2.8351 & 2.8531 \\
\hline
\end{tabular}

Table S13. Pbcn BPEA solid-state

\begin{tabular}{|c|c|c|c|c|}
\hline $\operatorname{Pbcn}\left(\mathrm{cm}^{-1}\right)$ & S0S1 & S1S0 & $\mathrm{CA}$ & $\mathrm{AC}$ \\
\hline S0S1 & 20888 & 510 & 494 & -94 \\
\hline S1S0 & 510 & 20888 & -94 & 494 \\
\hline $\mathrm{CA}$ & 494 & -94 & 28227 & 0 \\
\hline $\mathrm{AC}$ & -94 & 494 & 0 & 28227 \\
\hline \multicolumn{5}{|c|}{ eigenstates } \\
\hline & Excimer 1 & Excimer 2 & Excimer 3 & Excimer 4 \\
\hline Pbcn & S0S1 & S1S0 & $\mathrm{CA}$ & $\mathrm{AC}$ \\
\hline S0S1 & 0.7052 & -0.7059 & 0.0412 & -0.0525 \\
\hline S1S0 & -0.7052 & -0.7059 & 0.0412 & 0.0525 \\
\hline $\mathrm{CA}$ & -0.0525 & 0.0412 & 0.7059 & -0.7052 \\
\hline $\mathrm{AC}$ & 0.0525 & 0.0412 & 0.7059 & 0.7052 \\
\hline \multicolumn{5}{|c|}{ eigenvalues } \\
\hline Pbcn $(\mathrm{eV})$ & 2.0334 & 2.1375 & 2.825 & 2.8271 \\
\hline
\end{tabular}


Table S14. Me - DPP

\begin{tabular}{|c|c|c|c|c|}
\hline Me $\left(\mathrm{cm}^{-1}\right)$ & S0S1 & S1S0 & $\mathrm{CA}$ & $\mathrm{AC}$ \\
\hline S0S1 & 17984 & -400 & 126 & 975 \\
\hline S1S0 & -400 & 17984 & 975 & 126 \\
\hline $\mathrm{CA}$ & 126 & 975 & 22662 & 0 \\
\hline $\mathrm{AC}$ & 975 & 126 & 0 & 22662 \\
\hline \multicolumn{5}{|c|}{ eigenstates } \\
\hline & Excimer 1 & Excimer 2 & Excimer 3 & Excimer 4 \\
\hline Me & S0S1 & S1S0 & $\mathrm{CA}$ & $\mathrm{AC}$ \\
\hline S0S1 & -0.6924 & -0.6945 & 0.1328 & -0.1437 \\
\hline S1S0 & -0.6924 & 0.6945 & -0.1328 & -0.1437 \\
\hline $\mathrm{CA}$ & 0.1437 & -0.1328 & -0.6945 & -0.6924 \\
\hline $\mathrm{AC}$ & 0.1437 & 0.1328 & 0.6945 & -0.6924 \\
\hline \multicolumn{5}{|c|}{ eigenvalues } \\
\hline Me (eV) & 2.152015 & 2.259392 & 2.830006 & 2.83819 \\
\hline
\end{tabular}

Table S15. C6 - DPP

\begin{tabular}{|c|c|c|c|c|}
\hline C6 $\left(\mathrm{cm}^{-1}\right)$ & S0S1 & S1S0 & $\mathrm{CA}$ & $\mathrm{AC}$ \\
\hline S0S1 & 17984 & -692 & 1282 & 1596 \\
\hline S1S0 & -692 & 17984 & 1596 & 1282 \\
\hline $\mathrm{CA}$ & 1282 & 1596 & 23469 & 0 \\
\hline $\mathrm{AC}$ & 1596 & 1282 & 0 & 23469 \\
\hline \multicolumn{5}{|c|}{ eigenstates } \\
\hline & Excimer 1 & Excimer 2 & Excimer 3 & Excimer 4 \\
\hline C6 & S0S1 & S1S0 & $\mathrm{CA}$ & $\mathrm{AC}$ \\
\hline S0S1 & 0.658 & 0.7056 & 0.046 & 0.259 \\
\hline S1S0 & 0.658 & -0.7056 & -0.046 & 0.259 \\
\hline $\mathrm{CA}$ & -0.259 & 0.046 & -0.7056 & 0.658 \\
\hline $\mathrm{AC}$ & -0.259 & -0.046 & 0.7056 & 0.658 \\
\hline \multicolumn{5}{|c|}{ eigenvalues } \\
\hline C6 (eV) & 2.003596 & 2.313205 & 2.912461 & 3.050465 \\
\hline
\end{tabular}


Table S16. TEG -DPP

\begin{tabular}{|c|c|c|c|c|}
\hline TEG $\left(\mathrm{cm}^{-1}\right)$ & S0S1 & S1S0 & CA & $\mathrm{AC}$ \\
\hline S0S1 & 17984 & -509 & -197 & -666 \\
\hline S1S0 & -509 & 17984 & -666 & -197 \\
\hline $\mathrm{CA}$ & -197 & -666 & 26453 & 0 \\
\hline $\mathrm{AC}$ & -666 & -197 & 0 & 26453 \\
\hline \multicolumn{5}{|c|}{ eigenstates } \\
\hline & Excimer 1 & Excimer 2 & Excimer 3 & Excimer 4 \\
\hline TEG & S0S1 & S1S0 & CA & $\mathrm{AC}$ \\
\hline S0S1 & 0.7039 & 0.7059 & 0.0414 & -0.067 \\
\hline S1S0 & 0.7039 & -0.7059 & -0.0414 & -0.067 \\
\hline $\mathrm{CA}$ & 0.067 & -0.0414 & 0.7059 & 0.7039 \\
\hline $\mathrm{AC}$ & 0.067 & 0.0414 & -0.7059 & 0.7039 \\
\hline \multicolumn{5}{|c|}{ eigenvalues } \\
\hline TEG (eV) & 2.156603 & 2.289523 & 3.283447 & 3.290143 \\
\hline
\end{tabular}

Table S17. Ph - DPP

\begin{tabular}{|c|c|c|c|c|}
\hline $\mathbf{P h}\left(\mathrm{cm}^{-1}\right)$ & S0S1 & S1S0 & $\mathrm{CA}$ & $\mathrm{AC}$ \\
\hline S0S1 & 16452 & -686 & 435 & -330 \\
\hline S1S0 & -686 & 16452 & -330 & 435 \\
\hline $\mathrm{CA}$ & 435 & -330 & 20404 & 0 \\
\hline $\mathrm{AC}$ & -330 & 435 & 0 & 20404 \\
\hline \multicolumn{5}{|c|}{ eigenstates } \\
\hline & Excimer 1 & Excimer 2 & Excimer 3 & Excimer 4 \\
\hline $\mathbf{P h}$ & S0S1 & S1S0 & $\mathrm{CA}$ & $\mathrm{AC}$ \\
\hline S0S1 & 0.7069 & -0.6902 & -0.016 & -0.1537 \\
\hline S1S0 & 0.7069 & 0.6902 & -0.016 & 0.1537 \\
\hline $\mathrm{CA}$ & -0.016 & 0.1537 & -0.7069 & -0.6902 \\
\hline $\mathrm{AC}$ & -0.016 & -0.1537 & -0.7069 & 0.6902 \\
\hline \multicolumn{5}{|c|}{ eigenvalues } \\
\hline $\mathbf{P h}(\mathrm{eV})$ & 2.423559 & 2.608679 & 3.13726 & 3.163174 \\
\hline
\end{tabular}


Table S18. Bis-PDI1

\begin{tabular}{|c|c|c|c|c|}
\hline PDI1 $\left(\mathrm{cm}^{-1}\right)$ & S0S1 & S1S0 & $\mathrm{CA}$ & $\mathrm{AC}$ \\
\hline S0S1 & 18004 & 678 & 428 & 66 \\
\hline S1S0 & 678 & 18004 & 66 & 428 \\
\hline $\mathrm{CA}$ & 428 & 66 & 18082 & 0 \\
\hline $\mathrm{AC}$ & 66 & 428 & 0 & 18082 \\
\hline \multicolumn{5}{|c|}{ eigenstates } \\
\hline & Excimer 1 & Excimer 2 & Excimer 3 & Excimer 4 \\
\hline PDI1 & S0S1 & S1S0 & CA & $\mathrm{AC}$ \\
\hline S0S1 & -0.6562 & 0.3467 & 0.2635 & 0.6163 \\
\hline S1S0 & 0.6562 & 0.3467 & -0.2635 & 0.6163 \\
\hline $\mathrm{CA}$ & 0.2635 & -0.6163 & 0.6562 & 0.3467 \\
\hline $\mathrm{AC}$ & -0.2635 & -0.6163 & -0.6562 & 0.3467 \\
\hline \multicolumn{5}{|c|}{ eigenvalues } \\
\hline PDI1 (eV) & 2.1303 & 2.2076 & 2.2601 & 2.3509 \\
\hline
\end{tabular}

Table S19. Bis-PDI2

\begin{tabular}{|c|c|c|c|c|}
\hline PDI2 $\left(\mathrm{cm}^{-1}\right)$ & S0S1 & S1S0 & $\mathrm{CA}$ & $\mathrm{AC}$ \\
\hline S0S1 & 18004 & 554 & 547 & 697 \\
\hline S1S0 & 554 & 18004 & 697 & 547 \\
\hline $\mathrm{CA}$ & 547 & 697 & 18082 & 0 \\
\hline $\mathrm{AC}$ & 697 & 547 & 0 & 18082 \\
\hline \multicolumn{5}{|c|}{ eigenstates } \\
\hline & Excimer 1 & Excimer 2 & Excimer 3 & Excimer 4 \\
\hline PDI2 & S0S1 & S1S0 & $\mathrm{CA}$ & $\mathrm{AC}$ \\
\hline S0S1 & 0.4506 & 0.6898 & 0.1554 & 0.545 \\
\hline S1S0 & 0.4506 & -0.6898 & -0.1554 & 0.545 \\
\hline $\mathrm{CA}$ & -0.545 & 0.1554 & -0.6898 & 0.4506 \\
\hline $\mathrm{AC}$ & -0.545 & -0.1554 & 0.6898 & 0.4506 \\
\hline \multicolumn{5}{|c|}{ eigenvalues } \\
\hline PDI2 (eV) & 2.1145 & 2.1595 & 2.2462 & 2.4286 \\
\hline
\end{tabular}


Table S20. Bis-PDI3

\begin{tabular}{|c|c|c|c|c|}
\hline PDI3 $\left(\mathrm{cm}^{-1}\right)$ & S0S1 & S1S0 & CA & $\mathrm{AC}$ \\
\hline S0S1 & 18004 & 545 & 675 & 658 \\
\hline S1S0 & 545 & 18004 & 658 & 675 \\
\hline CA & 675 & 658 & 18082 & 0 \\
\hline $\mathrm{AC}$ & 658 & 675 & 0 & 18082 \\
\hline \multicolumn{5}{|c|}{ eigenstates } \\
\hline & Excimer 1 & Excimer 2 & Excimer 3 & Excimer 4 \\
\hline PDI3 & S0S1 & S1S0 & CA & $\mathrm{AC}$ \\
\hline S0S1 & 0.4548 & 0.7068 & -0.0193 & 0.5414 \\
\hline S1S0 & 0.4548 & -0.7068 & 0.0193 & 0.5414 \\
\hline CA & -0.5414 & -0.0193 & -0.7068 & 0.4548 \\
\hline $\mathrm{AC}$ & -0.5414 & 0.0193 & 0.7068 & 0.4548 \\
\hline \multicolumn{5}{|c|}{ eigenvalues } \\
\hline PDI3 $(\mathrm{eV})$ & 2.1032 & 2.1647 & 2.2421 & 2.4388 \\
\hline
\end{tabular}

Table S21. FE and CT contributions of BPEA and DPP solid state and PDI dimers

\begin{tabular}{cccccccccc}
\hline & $\begin{array}{c}\text { BPEA } \\
\text { C2/c }\end{array}$ & $\begin{array}{c}\text { BPEA } \\
\text { Pbcn }\end{array}$ & C6 & Me & TEG & Ph & PBI1 & PBI2 & PBI3 \\
\hline $\begin{array}{c}\mathrm{FE} \mid \\
|\mathrm{a}|^{2} /\left(\left.\mathrm{a}\right|^{2}+\left.\mathrm{b}\right|^{2}\right)\end{array}$ & 0.97 & 0.995 & 0.86 & 0.95 & 0.992 & 0.9995 & 0.86 & 0.41 & 0.41 \\
$\begin{array}{c}\mathrm{CT} \\
|\mathrm{b}|^{2} /\left(\left.\mathrm{a}\right|^{2}+\left.\mathrm{b}\right|^{2}\right)\end{array}$ & 0.03 & 0.005 & 0.14 & 0.05 & 0.008 & 0.0005 & 0.14 & 0.59 & 0.59 \\
\hline
\end{tabular}




\section{Triplet sensitization}

In order to obtain the range of the triplet excited state energy $\mathrm{E}\left(\mathrm{T}_{1}\right)$, two triplet sensitizers, $\mathrm{PdPc}(\mathrm{Obu})_{8}$ and $\mathrm{Pd}-\mathrm{NDP}$ were used. There was no sign of triplet energy transfer from $\mathrm{PdPc}(\mathrm{Obu})_{8}$ which has triplet energy of $1.12 \mathrm{eV} ;^{15}$ however, there is a triplet energy transfer from Pd-NDP which has a triplet energy of $1.30 \mathrm{eV}$ (Figure S26). ${ }^{16}$

Solutions of BPEA dimers and Pd-NDP were selectively excited using $560 \mathrm{~nm}$ (Figure S26). Upon the excitation of the porphyrin, singlet excited-state absorption (ESA) is observed at early times which then changes as the population undergoes intersystem crossing with the rate of $(2.5 \pm$ $0.2 \mathrm{ps})^{-1}$ to create ${ }^{3 *} \mathrm{Pd}-\mathrm{NDP}$. Triplet energy transfer then occurs via diffusion and the triplet ESA of BPEA dimers is observed after few $\mu$ s in the spectral region of $350 \mathrm{~nm}$ to $530 \mathrm{~nm}$. 

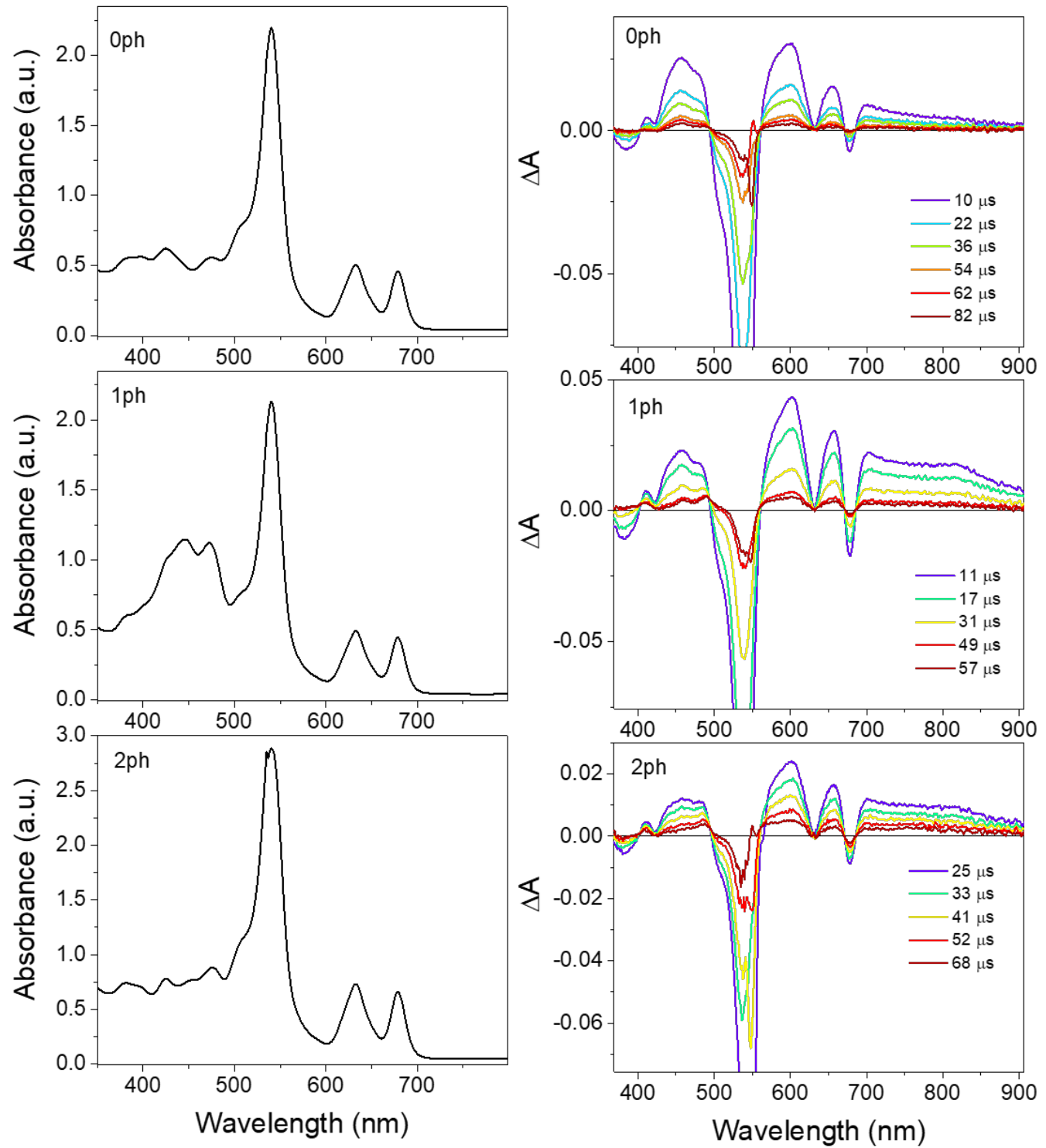

Figure S26. Steady-state absorbance and fsTA spectra of BPEA dimers mixed with triplet sensitizer, Pd-NDP in deoxygenated DCM excited at $560 \mathrm{~nm}(1 \mu \mathrm{J} / \mathrm{pulse})$. 


\section{Example input file for single-point energy of BPEA cation}

\$molecule
12
C $\quad-0.7102010571 \quad-3.6721717266 \quad-0.0011156782$
C $\quad-1.4000931783 \quad-2.4874046998 \quad-0.0009078810$
$\begin{array}{lllll}\text { C } & -0.7189151155 & -1.2337141551 & -0.0006988810\end{array}$
$\begin{array}{lllll}\text { C } & 0.7189070918 & -1.2337142907 & -0.0006927968\end{array}$
C $\quad \begin{array}{llll}1.4000856003 & -2.4874044755 & -0.0008913759\end{array}$
$\begin{array}{lllll}\text { C } & 0.7101938080 & -3.6721717051 & -0.0011066030\end{array}$
C $\quad-1.4292323305 \quad-0.0000668646 \quad-0.0004931462$
$\begin{array}{llll}\text { C } & 1.4292249804 & -0.0000678482 & -0.0004865439\end{array}$
$\begin{array}{lllll}\text { C } & 0.7189075270 & 1.2335792018 & -0.0003386371\end{array}$
$\begin{array}{lllll}\text { C } & -0.7189143391 & 1.2335792950 & -0.0003394250\end{array}$
$\begin{array}{lllll}\text { C } & -1.4000932819 & 2.4872685748 & -0.0001847549\end{array}$
$\mathrm{H} \quad-2.4847471201 \quad 2.4811024227 \quad-0.0001932338$
$\begin{array}{lllll}\text { C } & -0.7102016415 & 3.6720359680 & -0.0000405404\end{array}$
C $\quad 0.7101932530 \quad 3.6720361382 \quad-0.0000388752$
$\begin{array}{llll}\text { C } & 1.4000856563 & 2.4872691048 & -0.0001800650\end{array}$
H $\quad-1.2495884931 \quad-4.6154197212 \quad-0.0012831363$
$\mathrm{H} \quad-2.4847467051 \quad-2.4812396676 \quad-0.0009050427$
$\mathrm{H} \quad 2.4847392477 \quad-2.4812388215 \quad-0.0008756119$
$\mathrm{H} \quad 1.2495820878 \quad-4.6154192201 \quad-0.0012789395$
H $\quad-1.2495899147 \quad 4.6152834785 \quad 0.0000619672$
H $\quad 1.2495811018 \quad 4.6152839089 \quad 0.0000746907$
H $\quad 2.4847393513 \quad 2.4811038610 \quad-0.0001933603$
$\begin{array}{lllll}\text { C } & 2.8475567490 & -0.0000667211 & -0.0003809090\end{array}$
C $\quad 4.0667623539 \quad-0.0000571074 \quad-0.0002826660$
C $\quad-2.8475638998 \quad-0.0000642373 \quad-0.0004004191$
$\begin{array}{lllll}\text { C } & -4.0667694841 & -0.0000630065 & -0.0002963357\end{array}$
$\begin{array}{lllll}\text { C } & 5.4898049063 & -0.0000585874 & -0.0001772065\end{array}$
$\begin{array}{llll}\text { C } & 6.2085187795 & 1.2135964477 & 0.0003300305\end{array}$
$\begin{array}{lllll}\text { C } & 6.2085038649 & -1.2137319488 & -0.0005855611\end{array}$ 


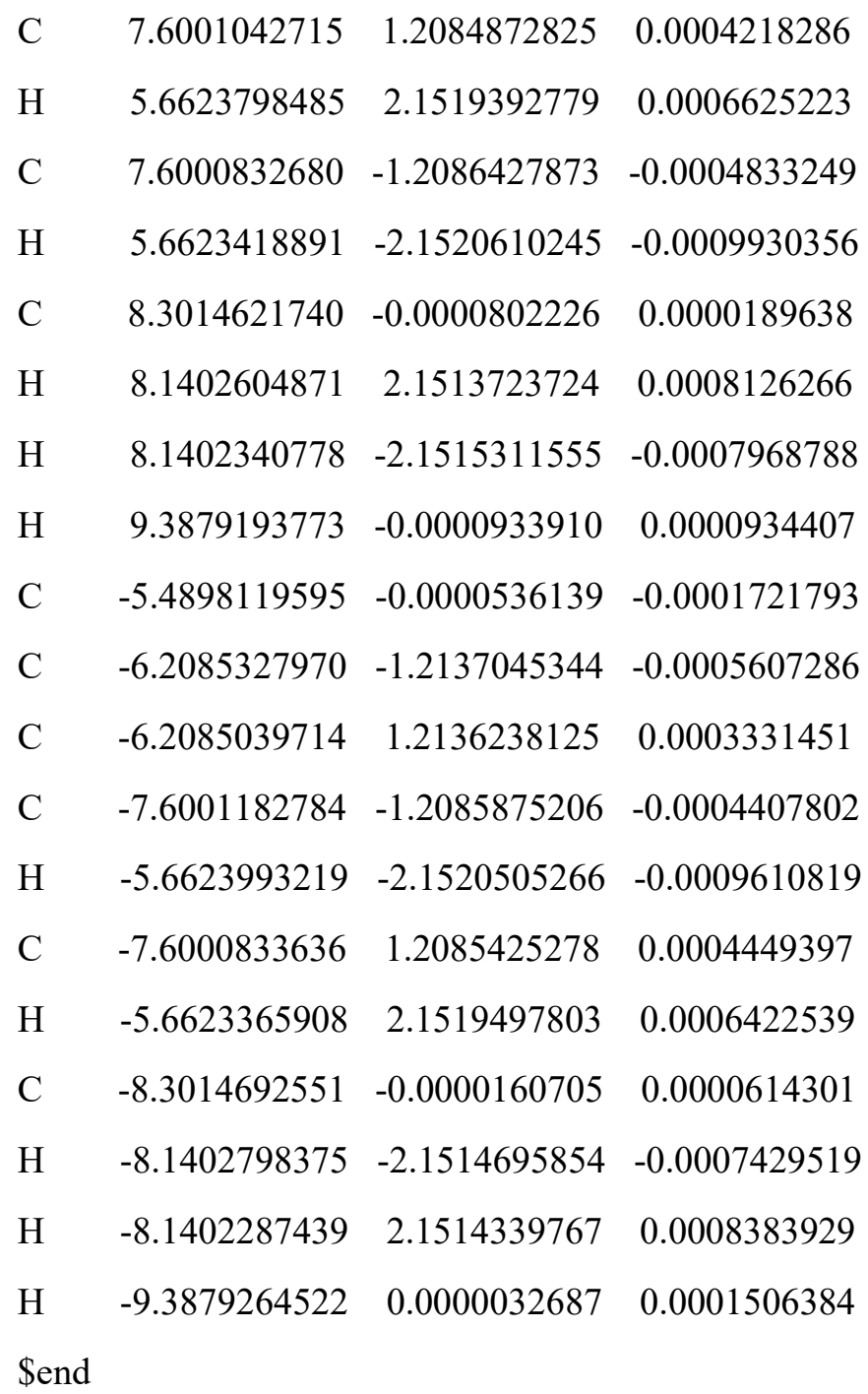


GUI

solvent_method pcm

\$end

$\$ p c m$

Theory CPCM

Method SWIG

Solver Inversion

Radii BONDI

\$end

\$solvent

Dielectric 38.25

OpticalDielectric 2.32288081

\$end 


\section{References}

1. Nesterov, E. E.; Zhu, Z.; Swager, T. M., Conjugation enhancement of intramolecular exciton migration in poly(p-phenylene ethynylene)s. J. Am. Chem. Soc. 2005, 127, 10083-10088.

2. Winters, M. U.; Pettersson, K.; Mårtensson, J.; Albinsson, B., Competition between superexchange-mediated and sequential electron transfer in a bridged donor-acceptor system. Chem. Eur. J. 2005, 11, 562-573.

3. Mauck, C. M.; Bae, Y. J.; Chen, M.; Powers-Riggs, N.; Wu, Y.-L.; Wasielewski, M. R., Charge-transfer character in a covalent diketopyrrolopyrrole dimer: Implications for singlet fission. ChemPhotoChem 2018, 2, 223-233.

4. Shao, Y.; Gan, Z.; Epifanovsky, E.; Gilbert, A. T. B.; Wormit, M.; Kussmann, J.; Lange, A. W.; Behn, A.; Deng, J.; Feng, X.; Ghosh, D.; Goldey, M.; Horn, P. R.; Jacobson, L. D.; Kaliman, I.; Khaliullin, R. Z.; Kuś, T.; Landau, A.; Liu, J.; Proynov, E. I.; Rhee, Y. M.; Richard, R. M.; Rohrdanz, M. A.; Steele, R. P.; Sundstrom, E. J.; Woodcock, H. L.; Zimmerman, P. M.; Zuev, D.; Albrecht, B.; Alguire, E.; Austin, B.; Beran, G. J. O.; Bernard, Y. A.; Berquist, E.; Brandhorst, K.; Bravaya, K. B.; Brown, S. T.; Casanova, D.; Chang, C.-M.; Chen, Y.; Chien, S. H.; Closser, K. D.; Crittenden, D. L.; Diedenhofen, M.; DiStasio, R. A.; Do, H.; Dutoi, A. D.; Edgar, R. G.; Fatehi, S.; Fusti-Molnar, L.; Ghysels, A.; Golubeva-Zadorozhnaya, A.; Gomes, J.; Hanson-Heine, M. W. D.; Harbach, P. H. P.; Hauser, A. W.; Hohenstein, E. G.; Holden, Z. C.; Jagau, T.-C.; Ji, H.; Kaduk, B.; Khistyaev, K.; Kim, J.; Kim, J.; King, R. A.; Klunzinger, P.; Kosenkov, D.; Kowalczyk, T.; Krauter, C. M.; Lao, K. U.; Laurent, A. D.; Lawler, K. V.; Levchenko, S. V.; Lin, C. Y.; Liu, F.; Livshits, E.; Lochan, R. C.; Luenser, A.; Manohar, P.; Manzer, S. F.; Mao, S.-P.; Mardirossian, N.; Marenich, A. V.; Maurer, S. A.; Mayhall, N. J.; Neuscamman, E.; Oana, C. M.; OlivaresAmaya, R.; O’Neill, D. P.; Parkhill, J. A.; Perrine, T. M.; Peverati, R.; Prociuk, A.; Rehn, D. R.; 
Rosta, E.; Russ, N. J.; Sharada, S. M.; Sharma, S.; Small, D. W.; Sodt, A.; Stein, T.; Stück, D.; Su, Y.-C.; Thom, A. J. W.; Tsuchimochi, T.; Vanovschi, V.; Vogt, L.; Vydrov, O.; Wang, T.; Watson, M. A.; Wenzel, J.; White, A.; Williams, C. F.; Yang, J.; Yeganeh, S.; Yost, S. R.; You, Z.-Q.; Zhang, I. Y.; Zhang, X.; Zhao, Y.; Brooks, B. R.; Chan, G. K. L.; Chipman, D. M.; Cramer, C. J.; Goddard, W. A.; Gordon, M. S.; Hehre, W. J.; Klamt, A.; Schaefer, H. F.; Schmidt, M. W.; Sherrill, C. D.; Truhlar, D. G.; Warshel, A.; Xu, X.; Aspuru-Guzik, A.; Baer, R.; Bell, A. T.; Besley, N. A.; Chai, J.-D.; Dreuw, A.; Dunietz, B. D.; Furlani, T. R.; Gwaltney, S. R.; Hsu, C.-P.; Jung, Y.; Kong, J.; Lambrecht, D. S.; Liang, W.; Ochsenfeld, C.; Rassolov, V. A.; Slipchenko, L. V.; Subotnik, J. E.; Van Voorhis, T.; Herbert, J. M.; Krylov, A. I.; Gill, P. M. W.; Head-Gordon, M., Advances in molecular quantum chemistry contained in the Q-chem 4 program package. Mol. Phys. 2015, 113, 184-215.

5. Tempelaar, R.; Reichman, D. R., Vibronic exciton theory of singlet fission. I. Linear absorption and the anatomy of the correlated triplet pair state. J. Chem. Phys. 2017, 146, 174703.

6. Hestand, N. J.; Spano, F. C., Interference between coulombic and ct-mediated couplings in molecular aggregates: $\mathrm{H}$ - to J-aggregate transformation in perylene-based $\pi$-stacks. $J$. Chem. Phys. 2015, 143, 244707.

7. López-Tarifa, P.; Liguori, N.; van den Heuvel, N.; Croce, R.; Visscher, L., Coulomb couplings in solubilised light harvesting complex II (LHCII): Challenging the ideal dipole approximation from tddft calculations. Phys. Chem. Chem. Phys. 2017, 19, 18311-18320.

8. Kasha, M.; Rawls, H. R.; El-Bayoumi, M. A., The exciton model in molecular spectroscopy. Pure Appl. Chem. 1965, 11, 371-392. 
9. Mauck, C. M.; Hartnett, P. E.; Margulies, E. A.; Ma, L.; Miller, C. E.; Schatz, G. C.; Marks, T. J.; Wasielewski, M. R., Singlet fission via an excimer-like intermediate in 3,6-bis(thiophen-2yl)diketopyrrolopyrrole derivatives. J. Am. Chem. Soc. 2016, 138, 11749-61.

10. Bae, Y. J.; Kang, G.; Malliakas, C. D.; Nelson, J. N.; Zhou, J.; Young, R. M.; Wu, Y. L.; Van Duyne, R. P.; Schatz, G. C.; Wasielewski, M. R., Singlet fission in 9,10bis(phenylethynyl)anthracene thin films. J. Am. Chem. Soc. 2018, 140, 15140-15144.

11. Quarti, C.; Fazzi, D.; Del Zoppo, M., A computational investigation on singlet and triplet exciton couplings in acene molecular crystals. Phys. Chem. Chem. Phys. 2011, 13, 18615-18625. 12. Kirkus, M.; Wang, L.; Mothy, S.; Beljonne, D.; Cornil, J.; Janssen, R. A. J.; Meskers, S. C. J., Optical properties of oligothiophene substituted diketopyrrolopyrrole derivatives in the solid phase: Joint J- and H-type aggregation. J. Phys. Chem. A 2012, 116, 7927-7936.

13. Kaufmann, C.; Bialas, D.; Stolte, M.; Würthner, F., Discrete $\pi$-stacks of perylene bisimide dyes within folda-dimers: Insight into long- and short-range exciton coupling. J. Am. Chem. Soc. 2018, 140, 9986-9995.

14. Miller, C. E.; Wasielewski, M. R.; Schatz, G. C., Modeling singlet fission in rylene and diketopyrrolopyrrole derivatives: The role of the charge transfer state in superexchange and excimer formation. J. Phys. Chem. C 2017, 121, 10345-10350.

15. Rihter, B. D.; Kenney, M. E.; Ford, W. E.; Rodgers, M. A. J., Synthesis and photoproperties of diamagnetic octabutoxyphthalocyanines with deep red optical absorbance. J. Am. Chem. Soc. 1990, $112,8064-8070$.

16. Galstyan, A.; Maurya, Y. K.; Zhylitskaya, H.; Bae, Y. J.; Wu, Y.-L.; Wasielewski, M. R.; Lis, T.; Dobrindt, U.; Stępień, M., П-extended donor-acceptor porphyrins and metalloporphyrins for antimicrobial photodynamic inactivation. Chem. Eur. J. 2020, 26, 8262-8266. 